\title{
AN INVESTIGATION ON STRUCTURAL PERFORMANCE OF PROFILED STEEL SHEET TO DEVELOP SELF-SUPPORTING ROOFING SYSTEM
}

\author{
S. M. Zahurul Islam*, A. A. Abang-Abdullah, M. S. Jafar \\ Housing Research Centre, Department of Civil Engineering, Universiti Putra Malaysia \\ *(Corresponding author: E-mail: smzislam190@yahoo.com)
}

\begin{abstract}
Profile steel shell structures are used popularly due to aesthetic and economical use of materials. The aim of this research work is to develop a self-supporting roofing element using profiled steel sheet such as zincalume, with potential for application in affordable quality housing. An analytical investigation using nonlinear finite element method is carried out on the structural strength and behaviour of different types of self-supporting roofing elements. An experimental study is conducted to validate the analytical investigation. Conventionally, profile steel sheet such as zincalume is using in roof as a covering materials using different types of internal support without any attention paid to their structural capability. Self-supporting of roofing system has significant advantages of removing the internal trussing and support. An attempt has been made to find out efficient, economic and aesthetically pleasing shape of shell elements to provide self- supporting roofing system on the basis of present results. The loaddeflection, stress- strain and deflected shape profiles for investigated roofing element is showed that parabolic roofing element having crown height $1 / 6$ of chord length is more efficient than others. It is observed that the proposed roofing system has a great potential to be exploited for housing construction.
\end{abstract}

Keywords: Structural performance, profiled steel sheet (zincalume), self-supporting, roofing element, semi-loof elements.

\section{INTRODUCTION}

The housing need is ever increasing due to rapid industrialization, urbanization and population explosion. The roof protects the building and its occupants from the effects of weather, but it are also is an architectural feature that gives the building a desired appearance.

Roof accounts to a substantial part (about 25\%) of the total cost of a building whether it is residential or industrial [1]. Therefore, it demands high technical and design specifications for both of the individual products elements and for the roof as a whole in order to achieve a satisfactory design life. Recent trends, research and developments are directed towards developing a lightweight, economical and structurally strong material that can be precast or prefabricated and easily erected. Conventionally, profile steel sheet such as zincalume and galvanized iron sheet is using in roof as a covering materials using different types of internal support without any attention paid to their structural capability. It is an innovative system that is self-supporting roofing system where sheeting roofs run continuous lengths of roof sheeting from one end to other end support through eliminating internal support. The use of the corrugated metal sheet goes back to the beginning of this century. For a long time, corrugated metal sheets were used as covering materials, without any attention paid to their structural capability. The reason for not considering them as structural elements was the lack of sound basis for using these sheets together to form a continuous self-supporting medium. This approach provides particularly neat and attractive roofing whilst eliminating the ridge capping, thereby avoiding any possibility of leakage along this fitting. The use of the corrugated metal thin shells in roofs, leads to considerable saving in materials, labour and cost. Analytically critical loads of self-supporting cylindrical roofs can be found out by energy theorem [2]. The possibility of using these sheets in folded plate roofs was investigated [3]. A study has been performed on structural strength and practical applications of cylindrical shell roofs made of corrugated metal sheets [4]. The exact differential equations used to explain the behavior of orthotropic shells. More recently, a study was carried out to develop a procedure for the design of 
steel roof subjected to non-uniform loads such as drifted snow using purlins frame [5]. Selfsupporting concept was not considered in their study. Rib steel deck ware used as a covering materials, without any attention paid to their structural capability. Geometric and materials nonlinearity also was ignored. Extensive study on support settlement of cylindrical shell roofs was carried out [6-8]. Experimentally an investigation on structural strength and behaviour of ferrocement semicircular roofing elements were conducted [9], Theoretical studies relating to ferrocement have been reported in the literature observed and found out an optimum shape within selected five shapes [10-11]. Thin cylindrical shell roof was solved [12] and was extensively used for checking the performance of various types of shell elements. They used support along the circumferential edge not straight edge as a self- supporting concept. Nonlinear analysis was not carried out. Steel instead of ferrocement is very much use now a day in the design of lighter structures. In ferrocement construction needs skilled, creative carpenters to produce good quality items with fine finishes. Zincalume is lighter than ferrocement, which is easier for construction, handling and efficiently erection. The self-supporting roofing element using profile steel sheeting (zincalume); a thin shell, lightweight structure, is a structural load bearing system describe in an earlier publication [13-14].

The main objective of this study is to develop a self-supporting roofing system, with potential and efficiency for application in affordable quality housing. Structural behavior of Inverted V shape, Cylindrical, Parabolic, Doubly curve, Single pitch and Flat plane shell roofing system are investigated analytically to provide as a self-supporting roofing system. This research was an attempt to investigate the contribution of corrugated sheet in reducing the buckling and displacement and enhances its load carrying capacity. An experimental program was undertaken in the course of present study. The experimental results showed good agreement with those obtained theoretically. The deflection and stress behavior of different types of roofing elements are compared each other. The efficient and economic shape of self-supporting roofing elements has been found out after a through investigation on the basis of present results.

\section{ROOFING MATERIAL ZINCALUME}

Shell structures are used popularly due to aesthetic and economical use of materials. Great variety of shell roofs have been designed and constructed in many part of the world [15]. The use of the shells in roofs, leads to considerable savings in materials. Normally corrugated metal sheet such as zincalume is used in roofs as a covering only, while depending on different types of intermediate support. A self-supporting roofing system is when a roof runs its continuous length from on end to other end support by eliminating internal supports such as purlins, rafter, fastener and truss. This method provides a particularly neat and attractive solution to roofing whilst eliminating the ridge capping, thereby avoiding any possibility of leakage along this fitting. This roof can save material, construction and erection cost.

The shape and size of precast/prefabricated roofing element is chosen to satisfy the general requirements of strength and stiffness, lightness and economy, ease of handle and erection, proper seating and leak proof joint. There are different types of materials for construction of roof frame and roof covering. Common types of materials are metal sheet, ferrocement, plastic, and concrete and clay tile for roof covering. Timber and metal are normally used for the trusses. For this investigation the corrugation metal sheet zincalume was chosen in an effort to develop the selfsupporting roofing system. The main features of using of zincalume sheet as roofing material as according to Bluescope-Lysaght are as follows: 
(a) Speedy installation; no shuttering required, less installation errors

(b) $\quad 30-40 \%$ cost saving over RCC roofing

(c) Lower dead load on the walls, light weight and easy handling

(d) High strength to weight ratio

(e) Easy to for into complex shapes, new shape more efficiently allowing to be used.

(f) Elegant profile and uniform sizes, large span possible with intermediate supports

(g) Abundantly available, and inexpensive and corrosion-resistant

(h) Fire registrant and material consistency high

(i) Unaffected by termites and longevity and does not required paint

(j) No materials wastage and recyclining system is applicable

(k) Economical considering mean service life

Zincalume sheet can be considered as the best and most durable roofing elements for affordable quality housing in the world. Zincalume consists of high strength steel substrate protected with corrosion inhibitive treatments and coatings designed to provide the broad spectrum of performance that is essential for long life and minimum maintenance. All steel sheets used in the manufacture of the roofing sheets shall have a protective metallic alloy coating of zinc $(43.5 \%)$, aluminium (55\%) and silicon (1.5\%), applied by the hot dip process and having a coating thickness of $0.05 \mathrm{~mm}$ as stipulated in AS1397-1993 for coating class AZ 150. Chromic acid sealed, zinc phosphate pretreatment is applied after alkaline cleaning for coating. Galvanized steel is treated on both sides with phosphate conversion coating followed by application of an impervious epoxy primer incorporating a corrosion inhibiting compound. Modified polyester coating of 20 micrometers is used for finish coat to ensure maximum durability. Composition layer of zincalume is shown in Figure 1.

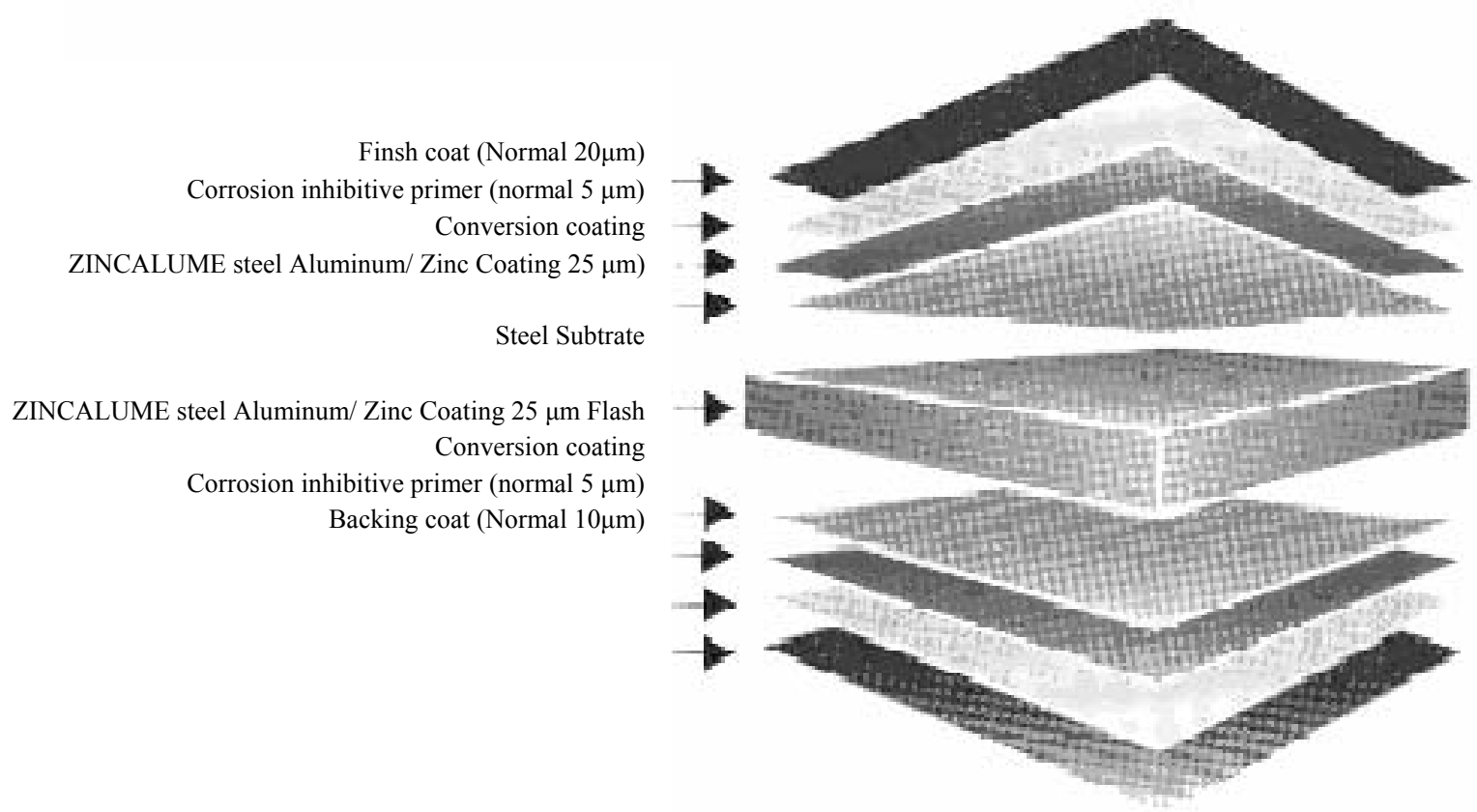

Figure 1. Different composition layer of zincalume sheet

Zincalume, which is used in the investigation, are locally available in Malaysia, Singapore and Australian market. It is obtained strength as steel grade ASTM A446 E, minimum yield strength $550 \mathrm{MPa}$, Modulus of elasticity $\mathrm{E}=210 \mathrm{GPa}$, poisons ratio $v=0.30:$ mass $=4.7 \mathrm{~kg} / \mathrm{m}^{2}$ (for thickness of $0.47 \mathrm{~mm}$ sheet). Zincalume obtained two basic strength grades G 550 and G 300, which are shown in Figure 2. High tensile steel G550 was used in this study to develop selfsupporting roofing elements. 


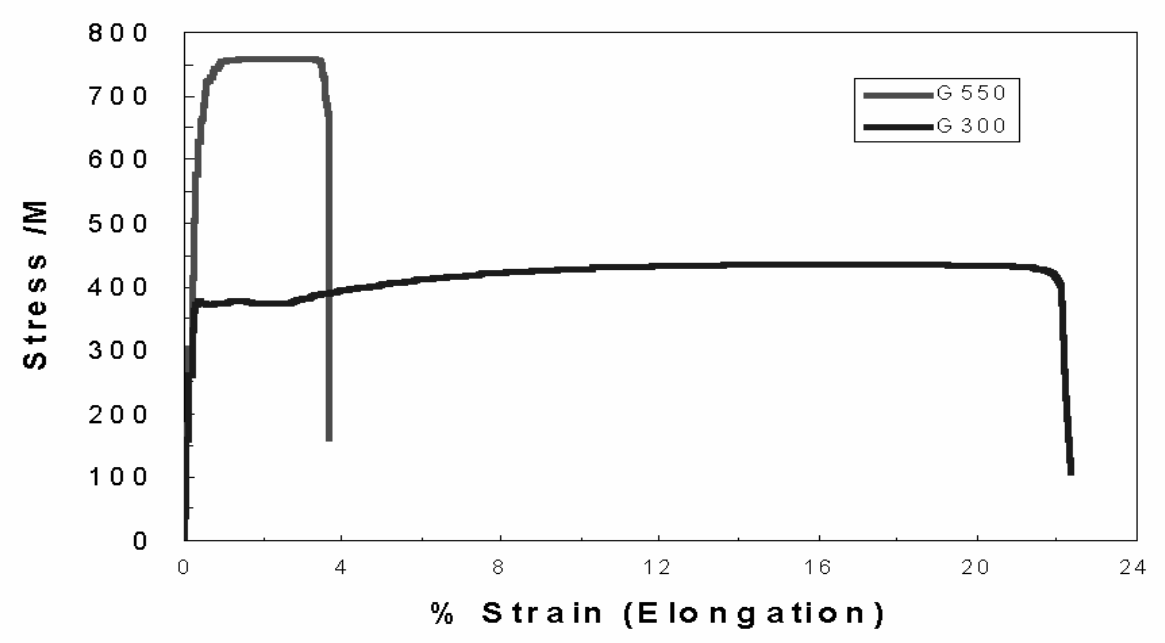

Figure 2. Stress-strain diagram for zincalume steel (Bluescope-Lysaght, 2003)

\section{FINITE ELEMENT MODELS}

The self-supporting roofing elements were models and analysed employing the finite element software (LUSAS) [16]. The shell-roofing element was analysed as a 3-D problem. It was discretised by means of 8-noded semi-loof elements having three translational displacements in the global axes at the corner and mid side nodes and one rotation with respect to axes in the plane of middle surface. The semi-loof element is probably one of the most efficient elements for the solution of thin shell of arbitrary geometry [17-18]. At first an arc was drown by three Cartesian points and then translate required width and corrugation for profile sheet. Width of different types of roofing elements was considered as $0.76 \mathrm{~m}$ and $8.0 \mathrm{~m}$ for analysis. Thickness of flat sheet and profile sheet were assigned as $1.2 \mathrm{~mm}$ and $0.47 \mathrm{~mm}$ respectively. A nonlinear FEM analysis was carried out assuming zincalume to be elastic-plastic material. The model was subjected to global distributed load along the vertical direction. Different types of roofing element such as Inverted V shape, Cylindrical, Parabolic, Doubly curve, Single pitch and Flat plane have been subjected to incremental global distributed load. The boundary conditions for the roofing element were assumed as fixed, pin and simple supported to make a comparative study of effect of boundary condition. Different mesh sizes and different numbers of element were tried so that accurate results could be obtained. Material and geometric nonlinearity were considered in FEM analysis. Three different types of profile sheet such as Trim, Spendek, and Klip-lok are model that is shown in Figures 3, 4, and 5.

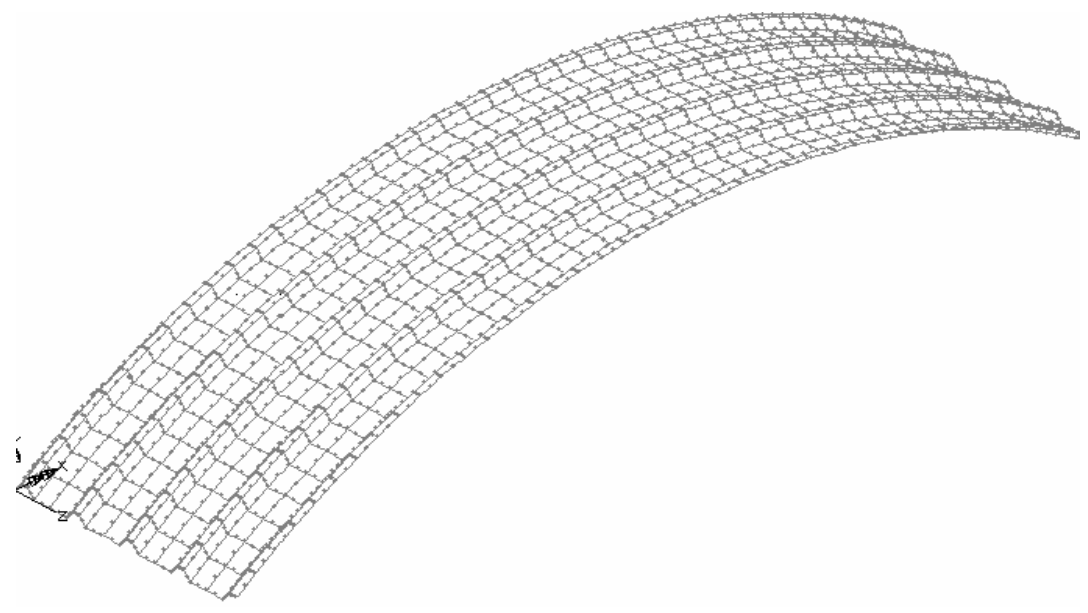

Figure 3. Finite element model of TRIM profile of parabolic shell roof 


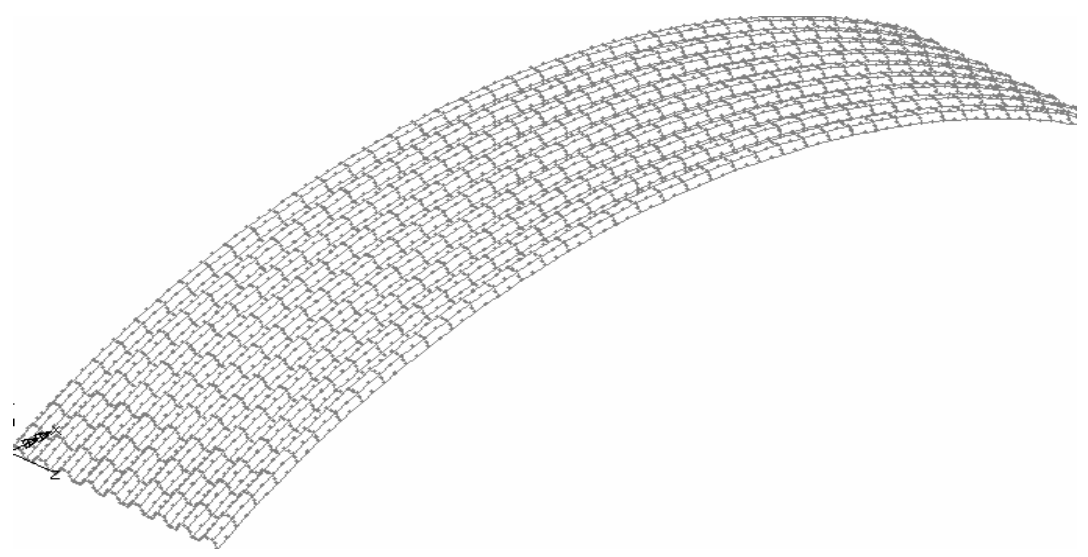

Figure 4. Finite element model of Spendek profile of parabolic shell roof

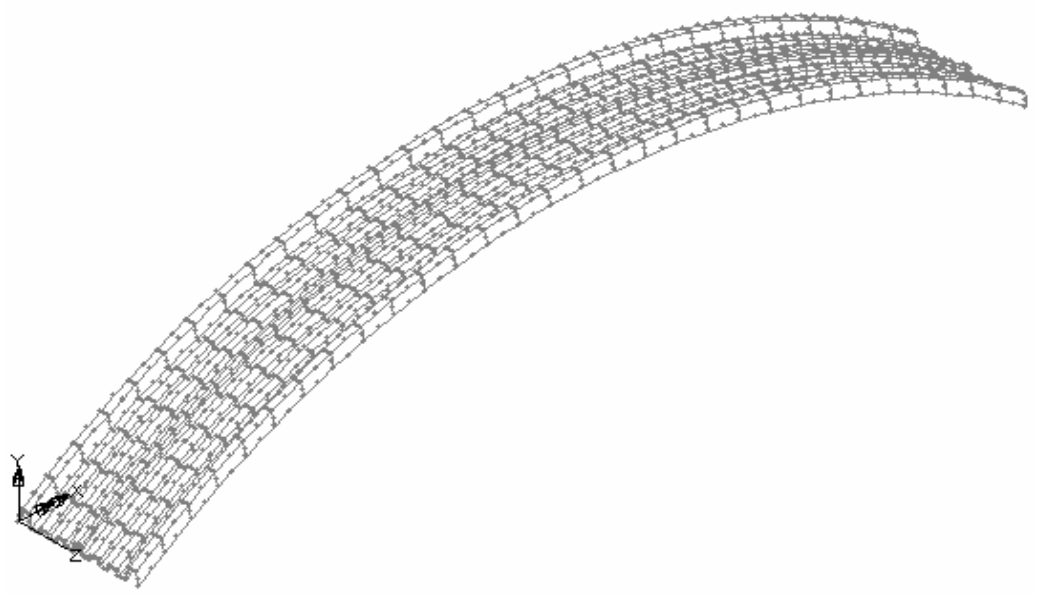

Figure 5. Finite element model of Klip-lok profile parabolic shell roof

\section{THEORETICAL FORMULATION OF DEGENERATED SHELL ELEMENT}

A good number of finite elements have been developed for the analysis of thin, circular cylindrical shells. These include flat elements and curved elements. Flat elements are lower- order elements and hence may require refined mesh, where as curved elements are higher -order elements and may more efficient than flat element [19]. The semi-loof element is probably one of the most efficient for the solution of thin shell of arbitrary geometry. It was originally published by Irons and since then it has been the object of much research with respect to its philosophy and performance in various structural situation. Finite element modeling of general shells has been using semi-loof elements, elements formulated on the basis of curved shell theory; and by means of degenerated isoparametric elements. The semi-loof shell element is a thin, doubly curved, isoparametric element formed by applying Kirchhoff constraints to a three-dimensional degenerated thick shell element (LUSAS). It is able to predict properly the bending performance of thin shell structures. The final nodal configurations are obtained corner and mid-side nodes at which displacement $\mathrm{U}, \mathrm{V}, \mathrm{W}$ along respectively the axis $\mathrm{X} . \mathrm{Y}, \mathrm{Z}$ is used as parameter: loof nodes at which the parameters are $\theta \mathrm{i}$ (rotation) which is shown in Figure 6.

The strain matrix B, relating the strain components in the local system to the element nodal variable can be constructed as $\quad \varepsilon=\sum_{k=1}^{n} B_{i} d_{i}$ 
Eq.(1) often written in the partitioned form

$$
\left[\begin{array}{l}
\varepsilon_{f} \\
\varepsilon_{s}
\end{array}\right]=\left[\begin{array}{l}
\sum_{k=1}^{n} B_{f i} d_{i} \\
\sum_{k=1}^{n} B_{s i} d_{i}
\end{array}\right]
$$

In which $\varepsilon_{\mathrm{f}}$ and $\varepsilon_{\mathrm{s}}$ is the in plain strains and the transverse shear strains. The total potential energy can be written as

$$
\Pi=\frac{1}{2} d^{T}\left[\int_{v_{e}} B^{T} D B d v\right] d=\frac{1}{2} d^{T}\left[\int_{v_{e}} B^{t}{ }_{f} D_{f} B_{f d v}\right] d+\frac{1}{2} d^{T}\left[\int_{v_{e}} B^{t}{ }_{s} D_{s} B_{s} d v\right] d
$$

Where the elasticity matrix $\mathrm{D}$ is divided into an in plane part $\mathrm{D}_{\mathrm{f}}$ and a transverse part $\mathrm{D}_{\mathrm{s}}$. Upon finite element discretisation and subsequent minimization of total potential energy [20-22] with respect to nodal variabled the following equations are obtained

$$
K_{i j} d_{j}=f_{i}
$$

In which the stiffness matrix $K_{i j}$ linking nodes $i$ and $j$ has the following typical contributions emanating from the in plane and transverse shear strain energy terms respectively.

$$
\begin{aligned}
K_{f i j}^{e} & =\int_{v_{e}} B^{T}{ }_{f i} D_{f} B_{f i} d v \\
K_{s i j}^{e} & =\int_{v_{e}} B_{s i}^{T} D_{s} B_{s j} d v
\end{aligned}
$$

A 2-point integration rule through the shell thickness and a full integration rule in the $\zeta-\eta$ surface can be used and

$$
d v=d x d y d z=|J| d \xi d \eta d \zeta
$$

Where $|\mathrm{J}|$ is determinant of the Jacobian matrix

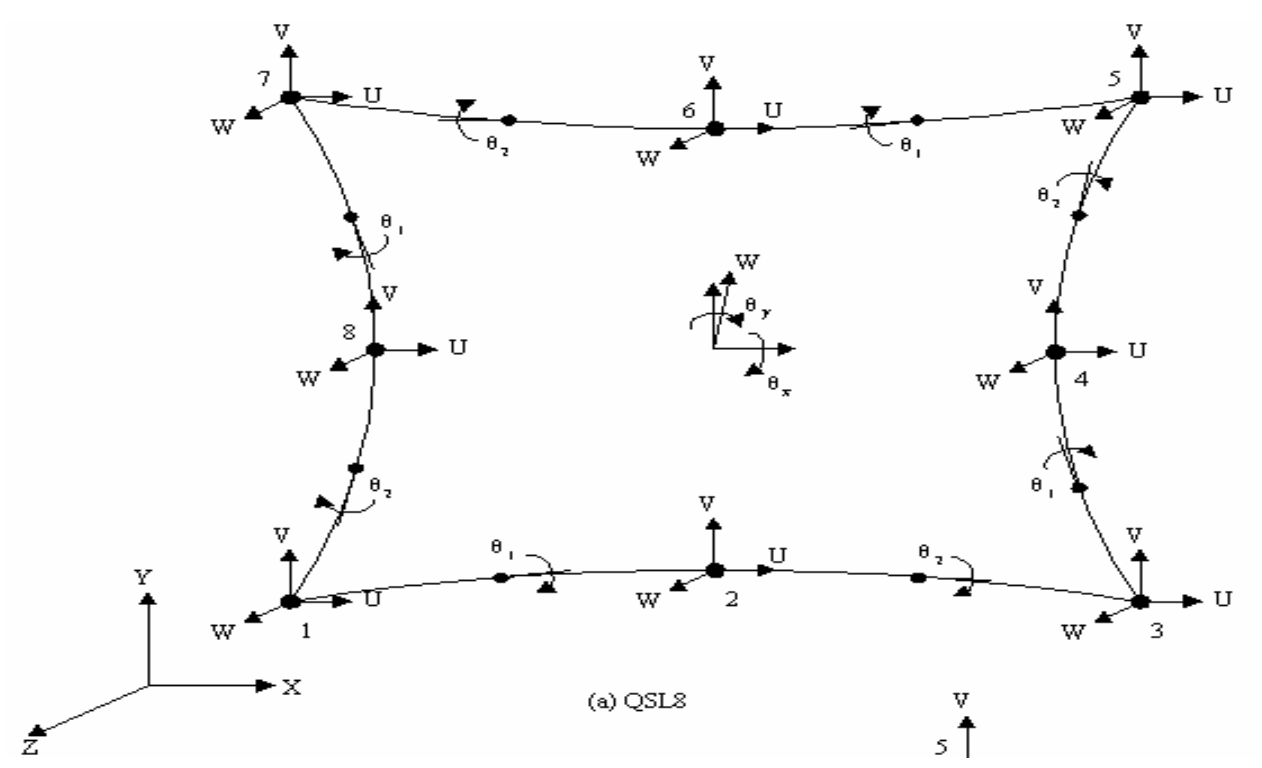

Figure 6. Final nodal configuration for Semi-loof elements

If the axes of the local coordinate system are parallel to those of the global coordinate system at all points in the shell mid surface, then the formulas for the shell element are the same as those of the Mindilin plate element. Shell structural behavior and strength is predicted in LUSAS by the following matrix: 


$$
\left[\begin{array}{l}
N_{x} \\
N_{y} \\
N_{x y} \\
M_{x} \\
M_{Y} \\
M_{x y}
\end{array}\right]=\left[\begin{array}{cccccc}
D_{1} & D_{2} & D_{4} & D_{7} & D_{11} & D_{16} \\
D_{2} & D_{3} & D_{5} & D_{8} & D_{12} & D_{17} \\
D_{4} & D_{5} & D_{6} & D_{9} & D_{10} & D_{18} \\
D_{7} & D_{8} & D_{9} & D_{10} & D_{14} & D_{19} \\
D_{11} & D_{12} & D_{13} & D_{14} & D_{15} & D_{20} \\
D_{16} & D_{17} & D_{18} & D_{19} & D_{20} & D_{21}
\end{array}\right]\left[\begin{array}{l}
\varepsilon_{x} \\
\varepsilon_{y} \\
\Gamma_{x y} \\
\Psi_{x} \\
\Psi_{y} \\
\Psi_{x y}
\end{array}\right]-\left[\begin{array}{l}
\varepsilon_{x o} \\
\varepsilon_{y o} \\
\Gamma_{x y o} \\
\psi_{x o} \\
\Psi_{y o} \\
\Psi_{x y o}
\end{array}\right]+\left[\begin{array}{l}
N_{x o} \\
N_{Y o} \\
N_{x y o} \\
M_{x o} \\
M_{y o} \\
M_{x y o}
\end{array}\right]
$$

where $\quad \mathrm{N} \quad$ are the membrane stress resultants (Force per unit width)

M are the flexural stress resultants (Moments per unit width)

$\mathrm{D} \quad$ are the Flexural and shear rigidies

E membrane strains

$\psi_{\mathrm{x}}, \psi_{\mathrm{y}}^{\prime}$ and $\psi_{\mathrm{xy}} \quad$ are the flexural strains in the local Cartesian system.

\section{NUMERICAL EXAMPLES AND RESULTS}

The primary effect of wind is visualized in the form of pressures normal to the structure's exterior surfaces. In this paper, the assessment of imposed load and wind loading was carried out according to Uniform Building by Law (Malaysian code of practice) [23] and the British code of practice [2426]. With the help of well-known FEM based software package LUSAS, different benchmark problem are solved. The LUSAS is used for the evaluation of deflection and stress-stran behavior of different types of roofing elements. The numerical results are studied for Parabolic, Cylindrical, Doubly Curve, Flat Plane and Single pitch roofing elements. The roofing elements are analyzed with span length $3 \mathrm{~m}$, width $0.76 \mathrm{~m}$ and thickness $0.47 \mathrm{~mm}$ and $1.2 \mathrm{~m}$ for profile sheet and flat sheet respectively [27] Different types of roofing elements are shown in Figure 7.

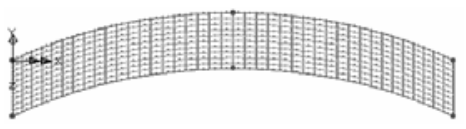

Parabolic shape

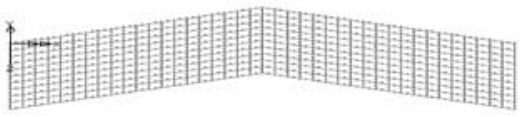

Inverted V shape

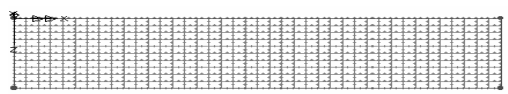

Flat plane shape

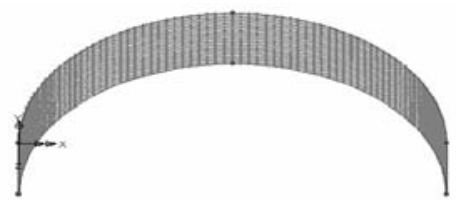

Cylindrical shape

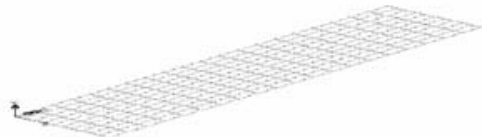

Single pitch shape

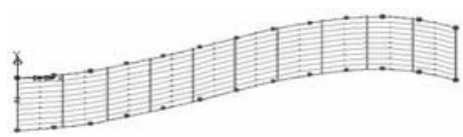

Doubly curve shape

Figure 7. Different types of roofing elements

The numerical results are studied for Parabolic, Cylindrical, Doubly Curve, Inverted V, Flat plane and Single pitch roofing system. The roofing shell elements are analyzed with span length $3 \mathrm{~m}$, width $0.76 \mathrm{~m}$ and thickness $0.47 \mathrm{~mm}$ and $1.2 \mathrm{~m}$ for profile sheet and flat sheet respectively. 


\section{EXPERIMENTAL INVESTIGATIONS}

In order to verify the validity of the finite element analysis of different types of roofing elements, critical and limited model test was conducted. The dimension of the model was span $3 \mathrm{~m}$, width $0.76 \mathrm{~m}$ and crown height $0.125 \mathrm{~m}, 0.25 \mathrm{~m}, 0.5 \mathrm{~m}, 1.0 \mathrm{~m}$ and $1.5 \mathrm{~m}$ respectively. All specimens were tested to ensure curve edge free and straight edge hinged. $U$ type metal channel were used to provide hinge support at straight of cylindrical and parabolic shell roofing element to maintain selfsupporting condition. All the specimens were tested in the vertical position. Sand bag loading was used to provide uniformly distributed load. Each bag was contained $5 \mathrm{~kg}$ load. The load was applied manually by gradually increased until yield failure of the model. Four deformation gauge, two LVDT and ten electronic strain gauges are used to measure deflection and stain. Deformation gauge and LVDT were set at the centre of bottom surface for the specimen with required stand. Strain gauges also were used the mid position of top surface of the specimen. Test setup was shown in Figures 8, 9, 10 and 11.

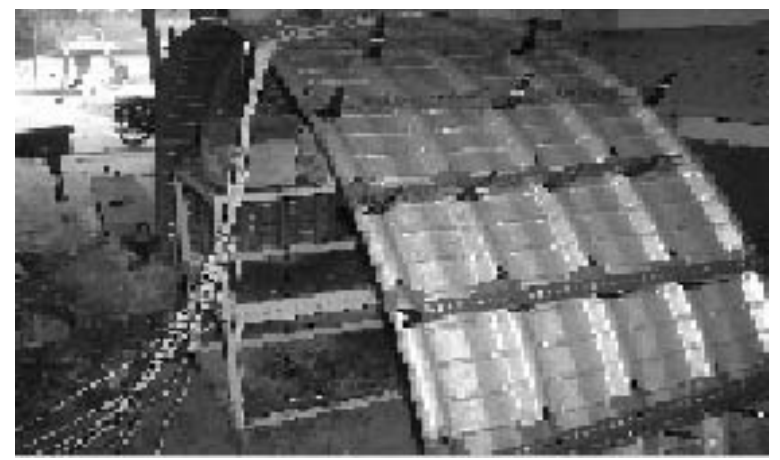

Figure 8. Test setup for cylindrical roofing element

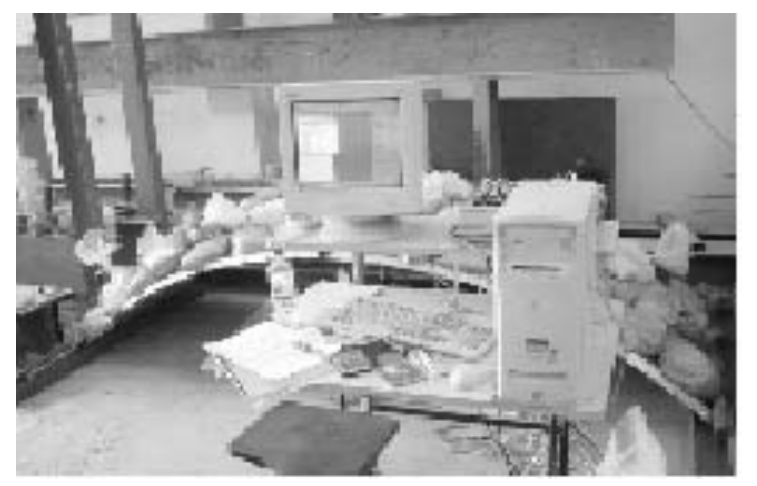

Figure 10. Test setup for parabolic shell roofing element

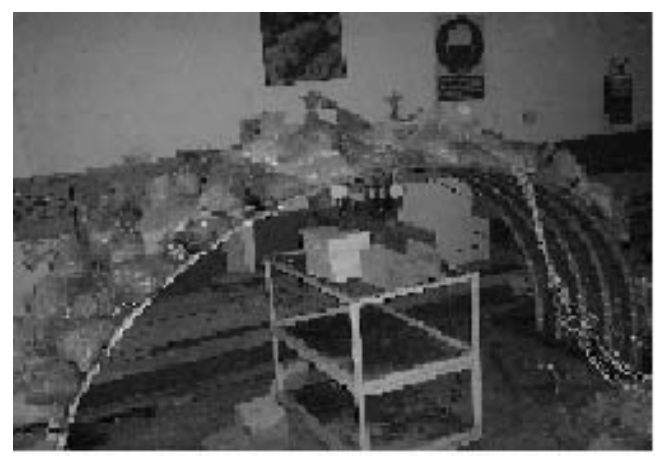

Figure 9. Sand bag loading on cylindrical roof

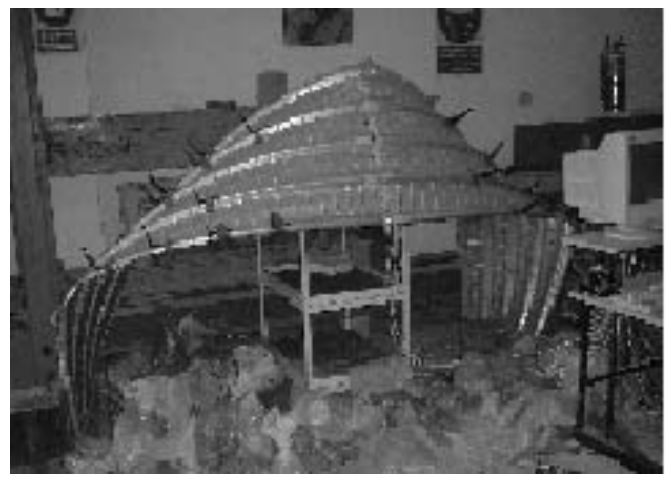

Figure 11. Experimental deflected shape of cylindrical roofing element

\section{RESULTS AND DISCUSSIONS}

The results were collected into two parts namely the finite element analysis (FEM) results and experimental results, which are then followed by the comparison section. The graphical representation of load deflection and stress-strain behavior of different types of roofing element is shown in Figures 12 and 13.

According to the non-linear finite analysis, parabolic shell roofing element is more efficient than other types of roofing element due to its less deflections and stresses. Parabolic and cylindrical roofing elements obtain arch action so load carrying capacity is higher those others as selfsupporting conditions. Nonlinear and non-planer parabolic system resist applied loads by direct 
stress, as opposed to membrane stress and bending stress. Experimental load-deflection profile of different crown heights parabolic roof using $0.47 \mathrm{~mm}$ thick corrugated zincalume sheet, $3 \mathrm{~m}$ span, $0.76 \mathrm{~m}$ width and pin support along the straight edge are shown in Figure 14.

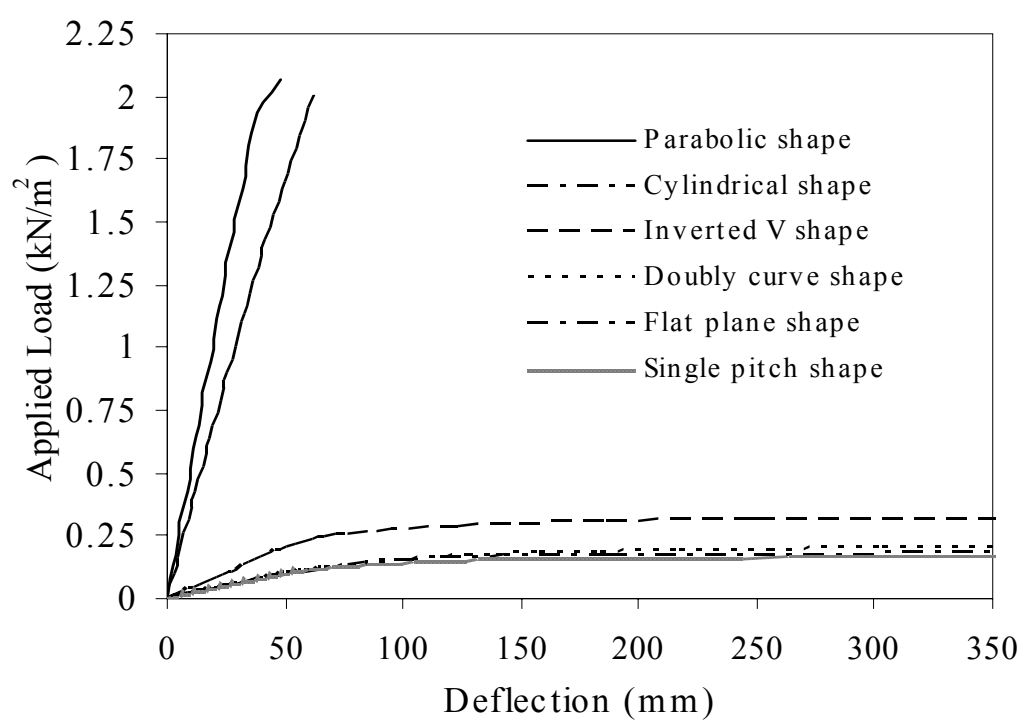

Figure 12. Load-deflection profile of different roofing element

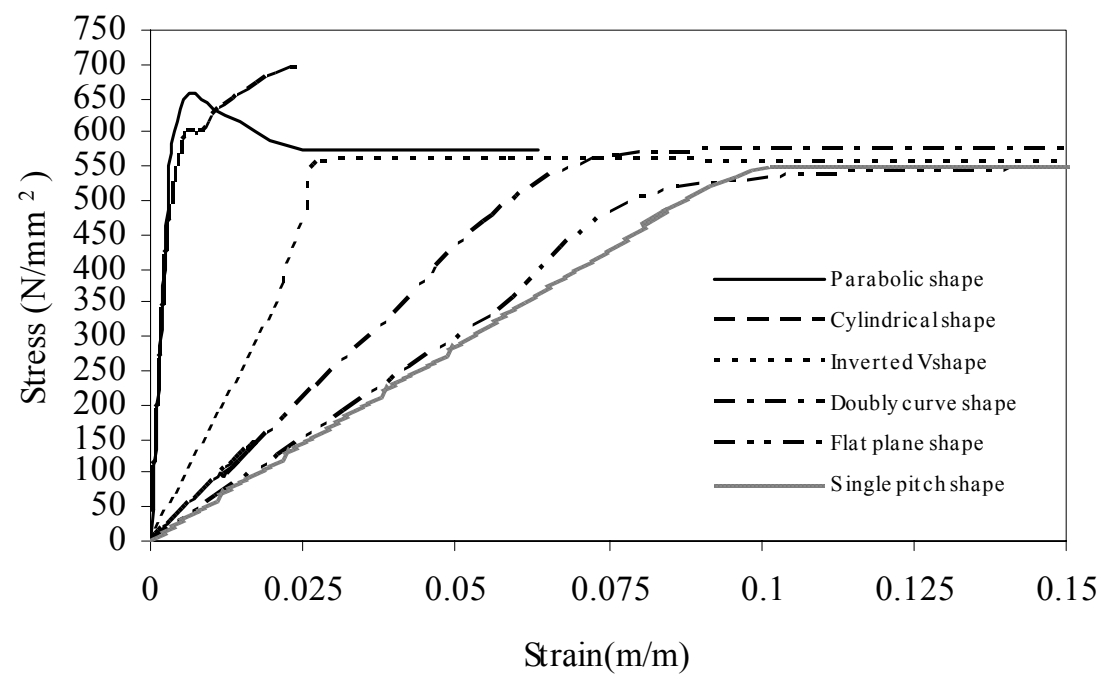

Figure 13. Stress strain profile of different types of roofing element

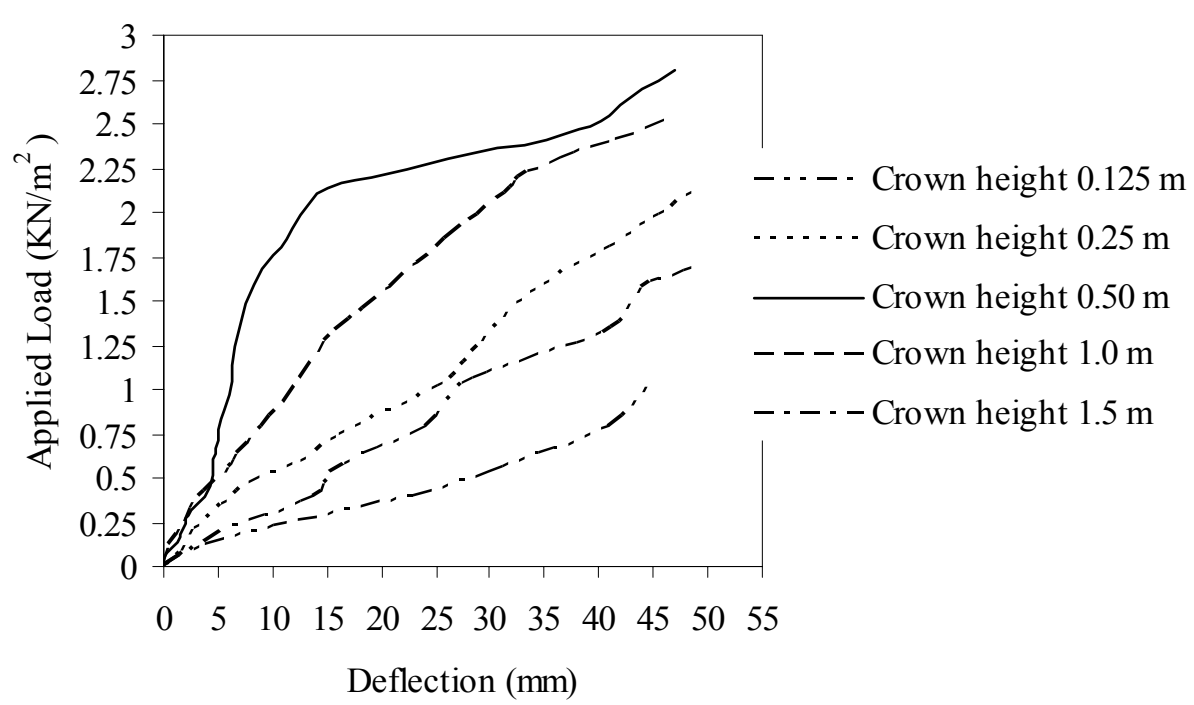

Figure 14. Experimental load deflection profile of different crown height parabolic shell roofing element 
Crown displacement is occurred due to two causes, (1) bending and (2) shortening of shell. Bending of shell is created by bending field such as $M_{x}, M_{y}, M_{x y}, M_{y x}, Q_{x}$, and $Q_{y}$ and on the other shortening is created by membrane field $N_{x}, N_{Y}, N_{x y}$, and $N_{y x}$. At crown height $1 / 6$ of chord width membrane field is predominant than bending field. As a result deflection is least. When crown height is lower membrane force also lower than bending force. When crown height increase membrane force also increases. After a certain limit of crown height membrane force also decrease. Load carrying capacity higher and least deflection was obtained at crown height $1 / 6$ of chord width or span length. In order to validate the analytical work, a comparison between the finite element analysis and experimental results are shown in Figures 15, 16, 17, 18 and 19. It is interesting to note that both the central deflection and stresses are lower in parabolic shape of roofing element with crown height of $0.5 \mathrm{~m}$. When crown height decrease then deflection and stresses increase i.e., valid for less crown height of $0.5 \mathrm{~m}$.

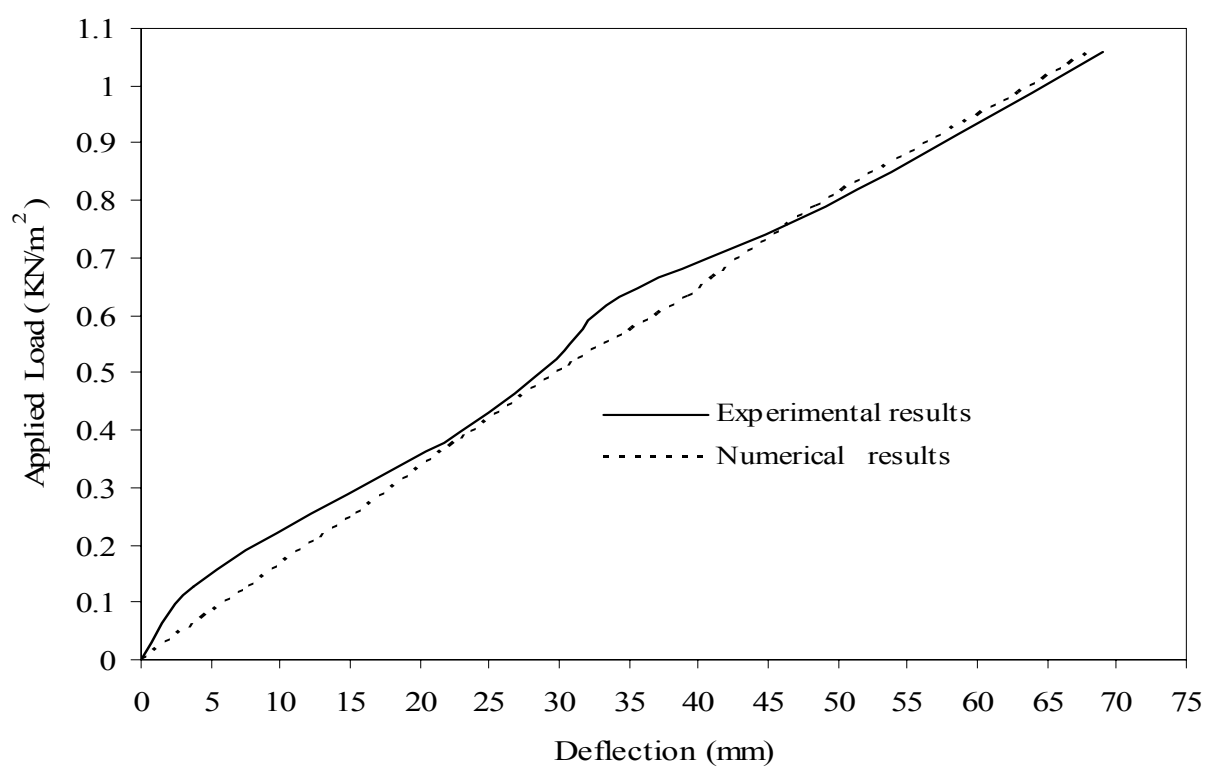

Figure 15. Load deflection profile at crown of parabolic roofing element for $0.125 \mathrm{~m}$ crown height

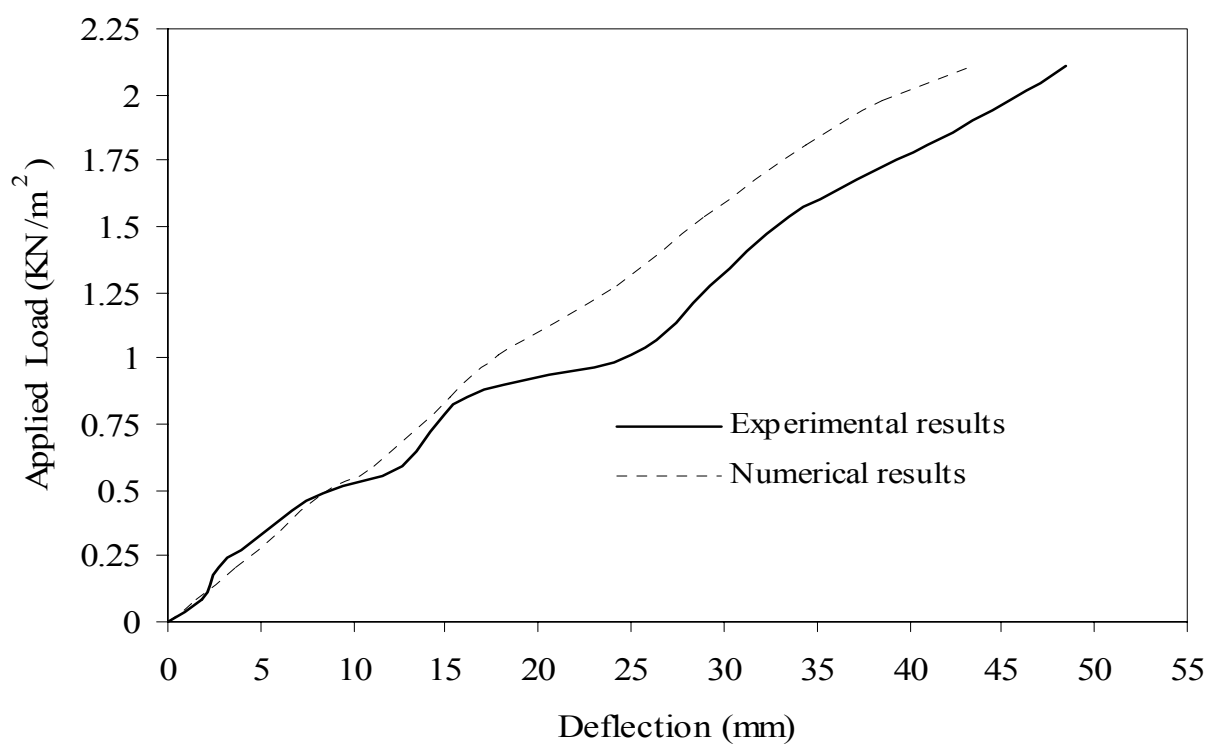

Figure 16. Load deflection profile at crown of parabolic roofing element for $0.25 \mathrm{~m}$ crown height 


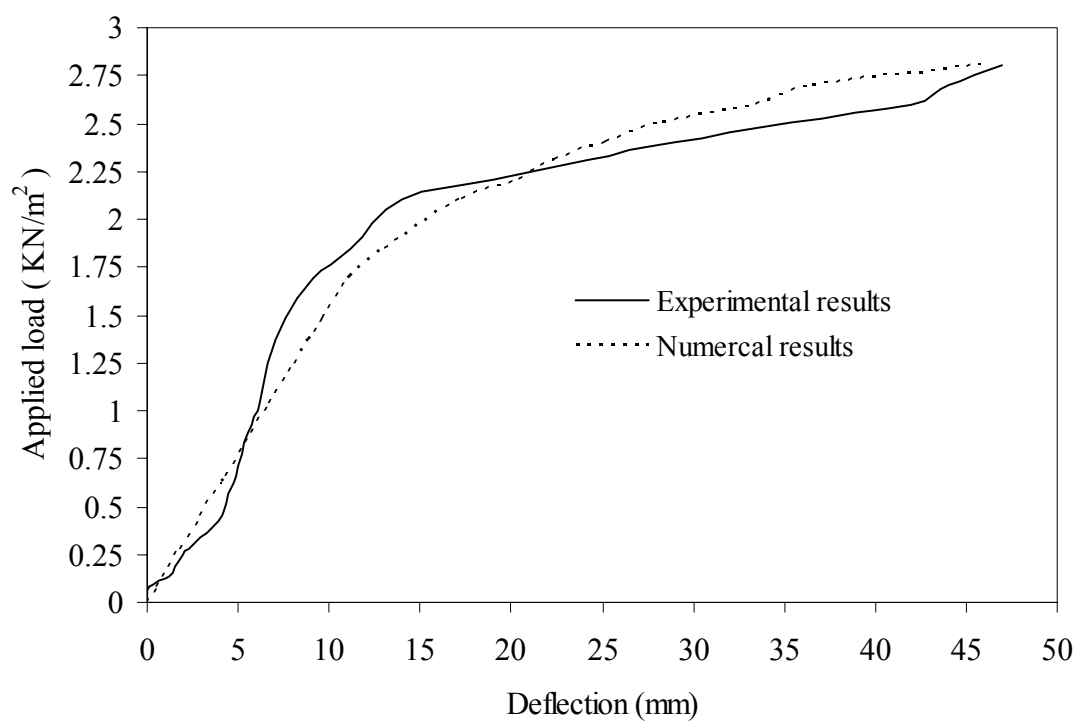

Figure 17. Load deflection profile at crown of parabolic roofing element for $0.5 \mathrm{~m}$ crown height

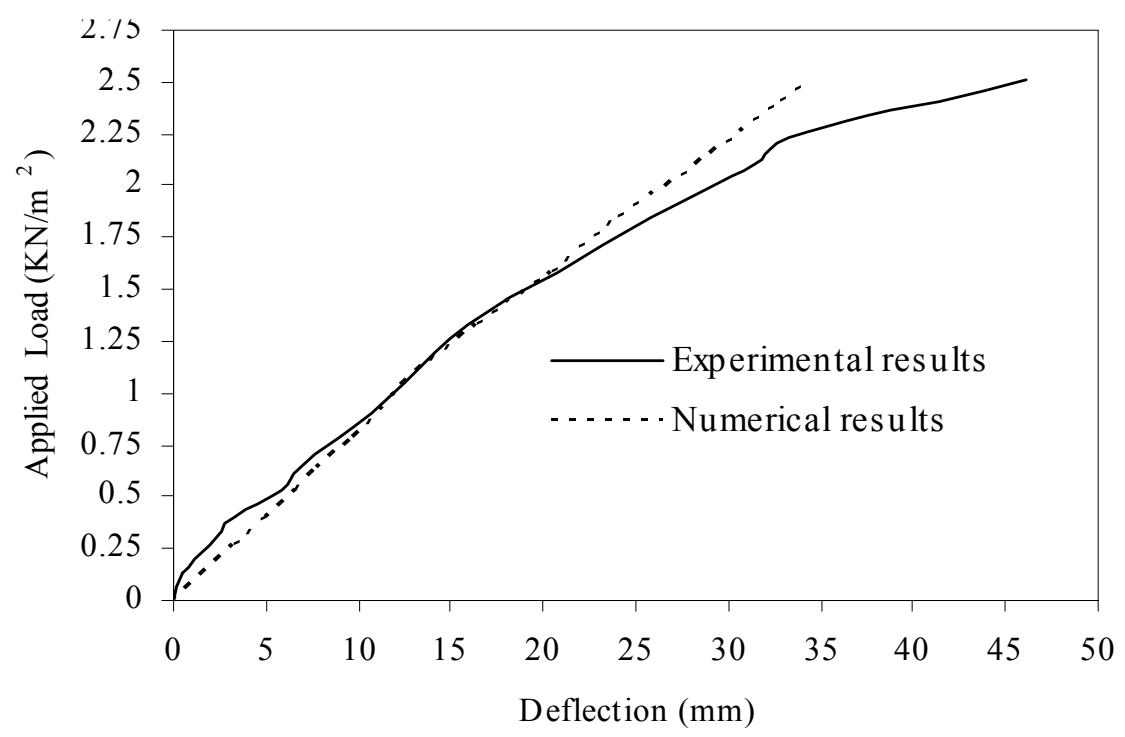

Figure 18. Load deflection profile at crown of parabolic roofing element for $1.0 \mathrm{~m}$ crown height

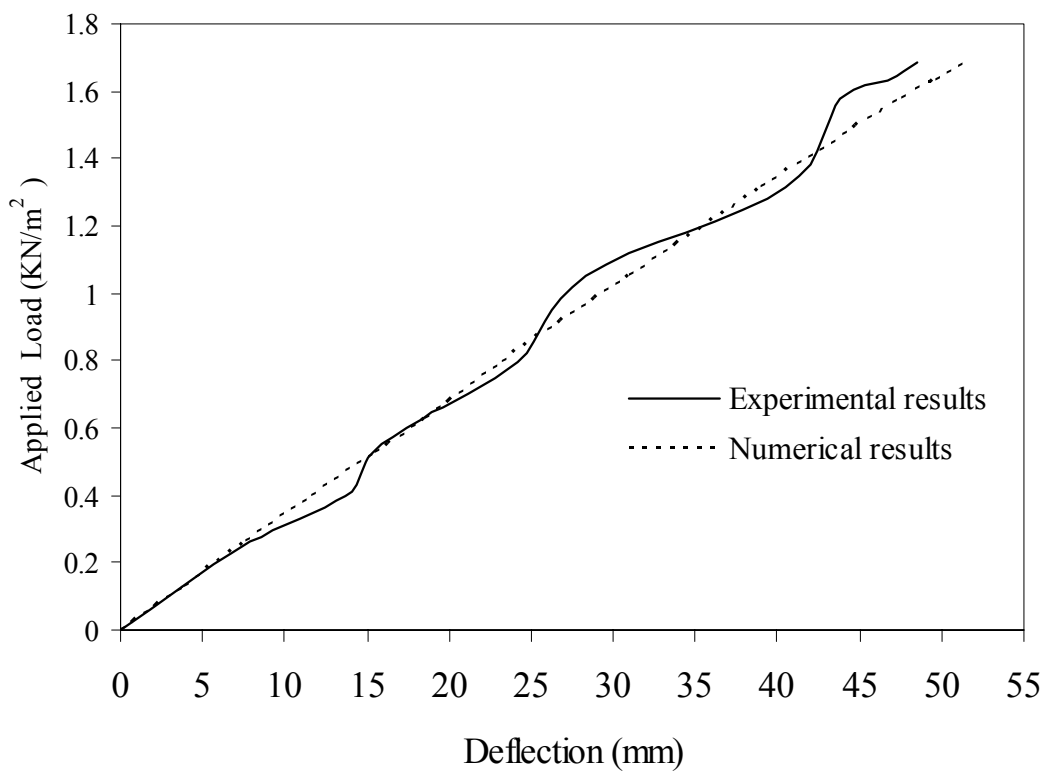

Figure 19. Load deflection profile at crown of parabolic roofing element for $1.5 \mathrm{~m}$ crown height 
The results showed load carrying capacity, deflection and stresses in parabolic roofing shell elements with different crown height. Load carrying capacity was 1.059, 2.108, 2.80, 2.508 and $1.684 \mathrm{kN} / \mathrm{m}^{2}$ without geometrical failure for $0.125,0.25,0.5,1.0$ and $1.5 \mathrm{~m}$ crown height parabolic and cylindrical roofing element respectively. Geometrical as well as yield failure load was found due to $1.283,2.23,3.164,2.71,1.739 \mathrm{kN} / \mathrm{m}^{2}$ for $0.125,0.25,0.5,1.0$ and $1.5 \mathrm{~m}$ crown height parabolic and cylindrical roofing element respectively.

Since the surface area also increases with the crown height, it is found that optimum crown height will be more economical due to materials. Both end fixed and pin support showed almost same results with minor changes. Horizontal displacement of simple supported condition was more than that of pin and fixed supporting condition. The behaviour of this structure depends on the loadtransferring action of its member and connection. The graphical representation of stress-strain behaviour of selected roofing element is shown in Figures 20, 21 and 22.

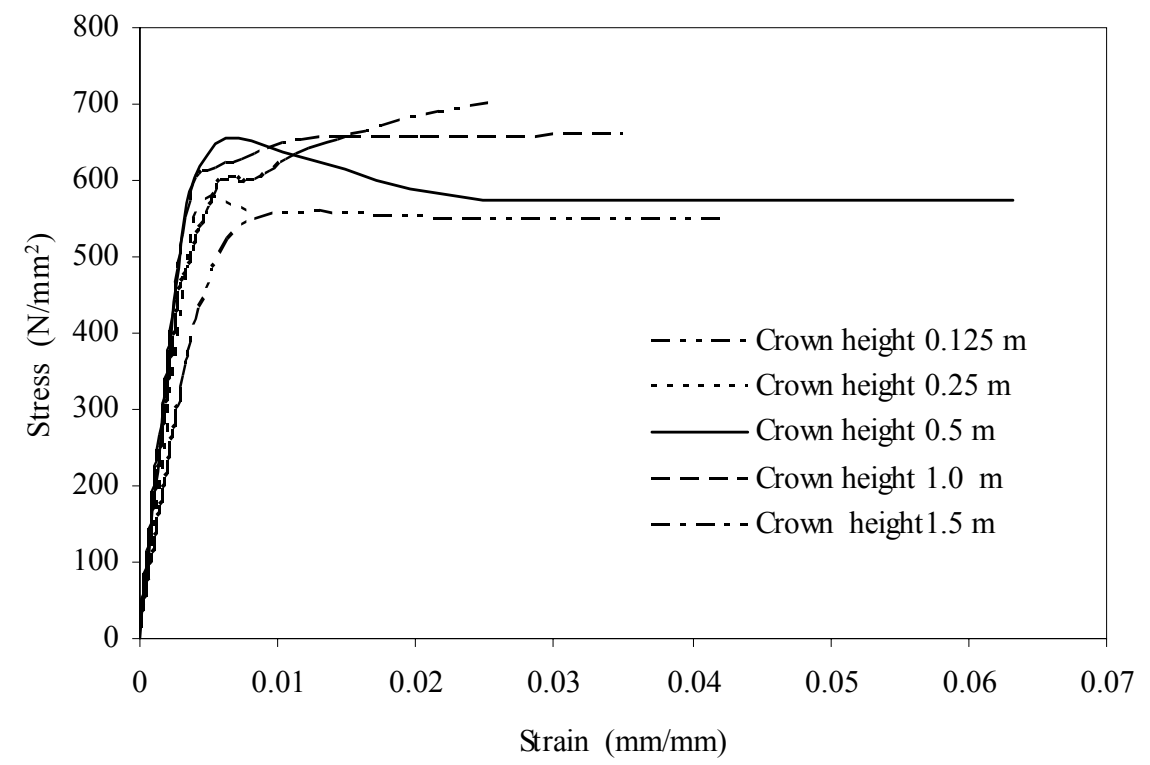

Figure 20. Stress strain profile of different crown height parabolic roofing element

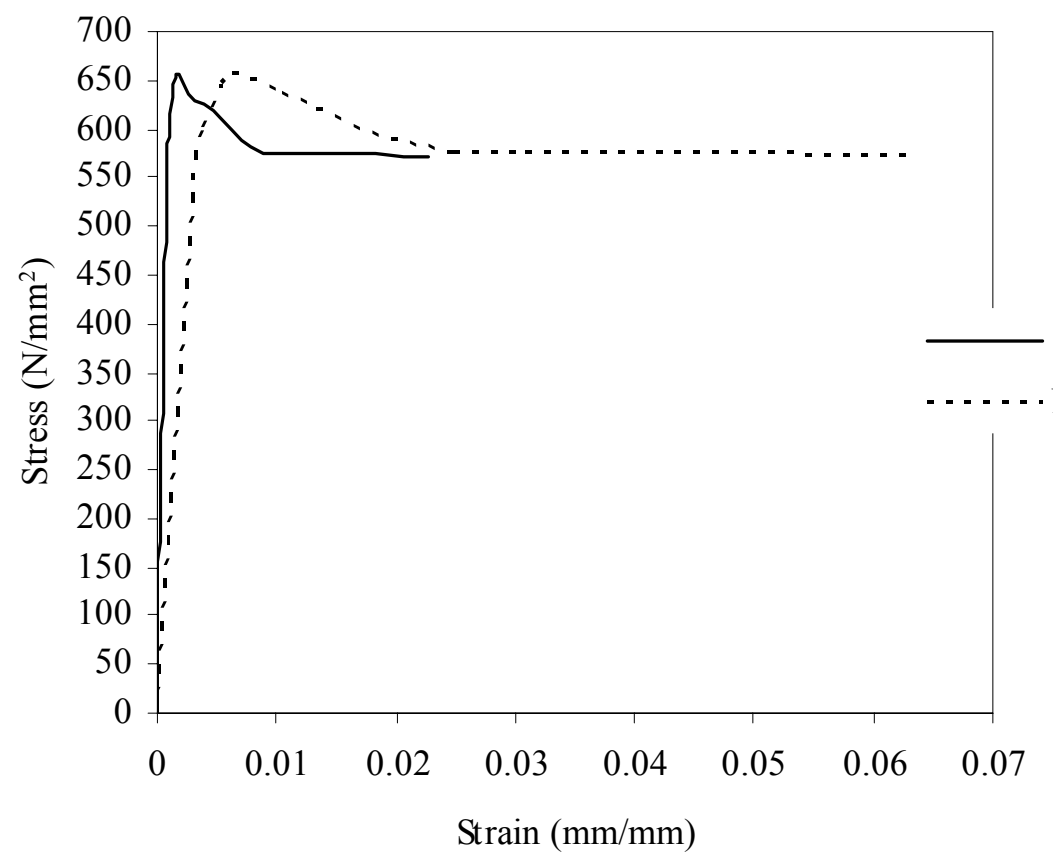

Figure 21. Stress strain profile of crown height $0.5 \mathrm{~m}$ parabolic roofing element 


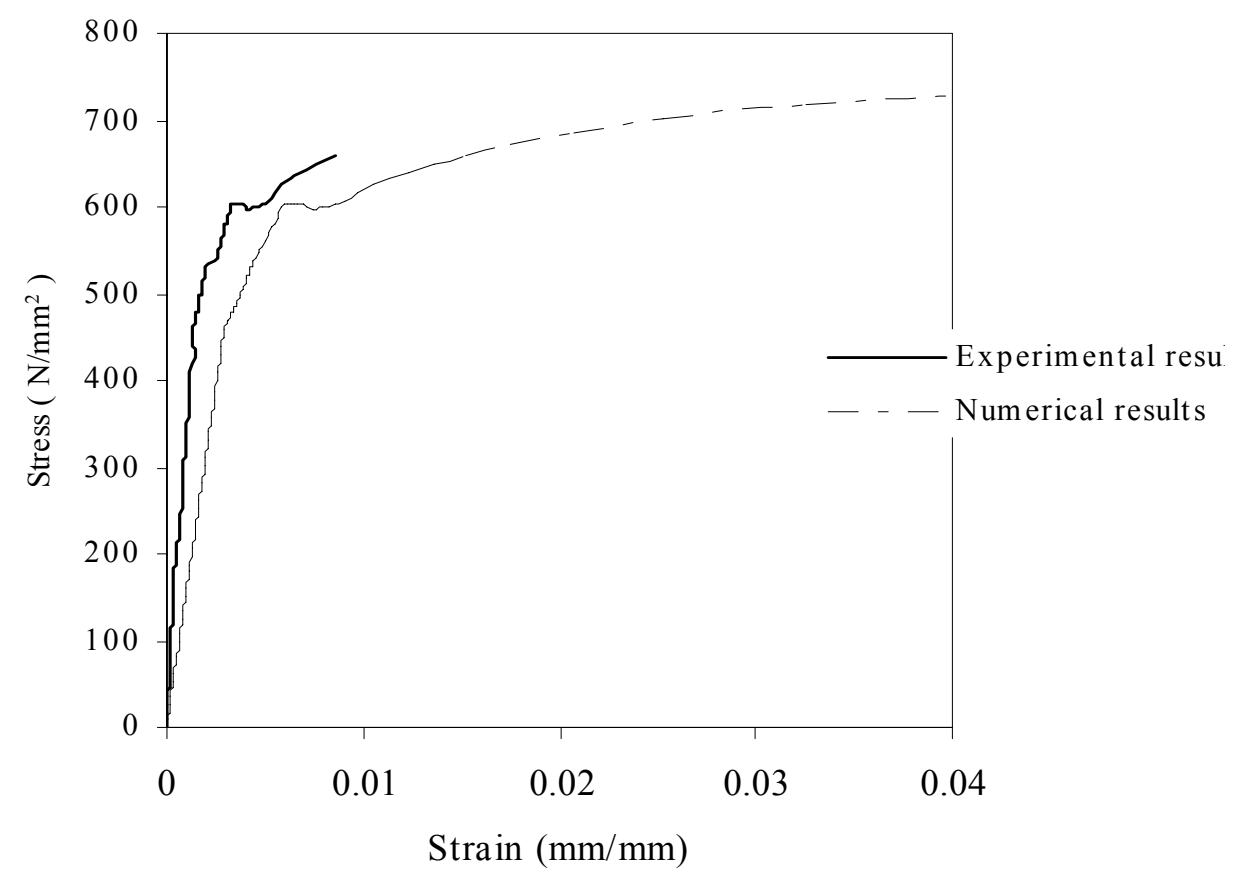

Figure 22. Stress strain profile of crown height $1.0 \mathrm{~m}$ parabolic roofing element

Nine types of roofing elements are studies in the present work. The presence of corrugation in the metal roofing element resulted in a significant improvement on the roof's structural performance compared to flat sheet element.

Good agreement was found between the results from non-linear analysis and those obtained experimentally. The load -deflection, stress strain and deflected shape profiles for investigated roofing element showed that parabolic roofing element having crown height $1 / 6$ of chord width is more efficient than others as self supported condition. It was observed that a parabolic shape roofing element with optimum crown height was structurally and economically able to use as a selfsupport roofing system for $8 \mathrm{~m}$ span lengths using $1.2 \mathrm{~mm}$ thick corrugated zincalume. Deflection along the arc length of different crown height of parabolic shell roof is shown in Figure 23 due to service load $0.528 \mathrm{kN} / \mathrm{m}^{2}$. Form the analysis, it was seen that maximum deflection obtained at the center point of curve roofing element.

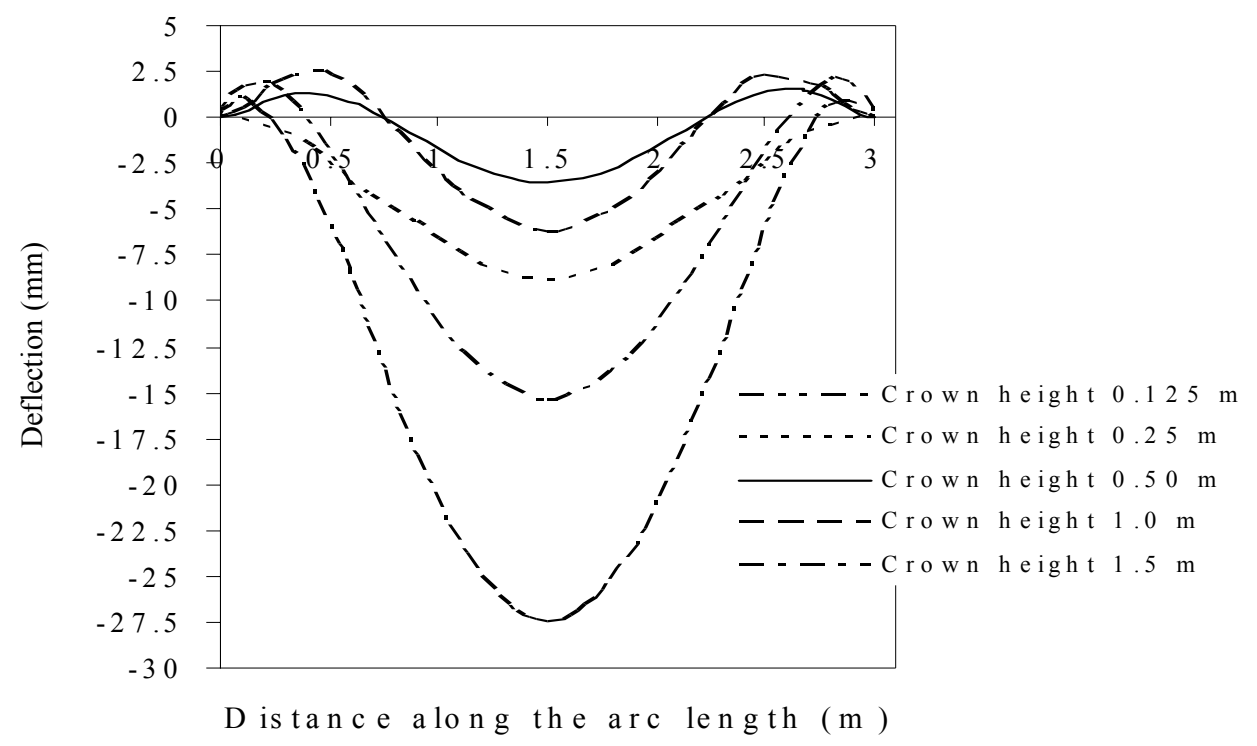

Figure 23. Deflection profile of different crown height parabolic roofing element along the arc length 
It was observed that both the central deflection and stresses are lower parabolic shape of roofing element with crown height of $0.5 \mathrm{~m}$. When crown height decreased then deflection and stresses increased i.e., valid for lower crown height of $0.5 \mathrm{~m}$. The results showed optimum crown height, deflection and stresses in parabolic roofing shell elements. Since the surface area also increases with the crown height, it was found that optimum crown height would be more economical due to materials.

Nine types of roofing elements are studies in the present work. It was found that support condition has a great impact on behavior of shell structure. Both end fixed and pin support showed almost same results with minor changes. Horizontal displacement of simple supported condition was more than that of pin and fixed supporting condition. Figure 4 shows different shapes of roofing elements; Doubly curve shape of roofing element is architecturally beautiful. The parabolic roofing element is suitable to use as a self- supporting roofing system up to $8 \mathrm{~m}$. On the basis of the present analysis, it is found that the corrugated parabolic roofing element is the most economical, efficient, architecturally pleasing shape in self- supporting condition. Three types of profile sheet were analyzed which deflection behaviour is shown in Table1.

Table 1. Deflection of different types of profile sheet

\begin{tabular}{|c|c|c|c|c|}
\hline \multirow{2}{*}{$\begin{array}{c}\text { Thickness of } \\
\text { Materials (mm) }\end{array}$} & $\begin{array}{c}\text { Applied load for } \\
\text { Analysis kN/ m }\end{array}$ & TRIM profile & Spandek profile & Klip-lok \\
\cline { 3 - 5 } & 0.528 & 4.99 & 4.52 & 5.13 \\
0.47 & 0.633 & 5.98 & 5.42 & 6.16 \\
(Profile Sheet) & 0.950 & 8.98 & 8.13 & 9.23 \\
\hline
\end{tabular}

In shell elements, it was observed that corrugated sheet is structurally 10 times stiffer than flat sheet, which is shown in Table 2. Profile sheet is stronger because of its rib and section modulus. Generally, based on the results obtained, the objectives of this work have been achieved where the parabolic corrugated steel roofing element was able to show good structural performance under self-supporting condition.

Table 2. Displacement of parabolic roofing elements with different span length

\begin{tabular}{|c|c|c|c|c|c|c|c|}
\hline \multirow{3}{*}{ Roofing System } & \multirow{3}{*}{ Thickness (mm) } & \multirow{3}{*}{$\begin{array}{c}\text { Load } \\
\mathrm{kN} / \mathrm{m}^{2}\end{array}$} & \multicolumn{5}{|c|}{ Span length (m) } \\
\hline & & & 3 & 4 & 5 & 6 & 7 \\
\hline & & & \multicolumn{5}{|c|}{ Deflection (mm) } \\
\hline \multirow{2}{*}{$\begin{array}{l}\text { Parabolic shell } \\
\text { roof }\end{array}$} & 0.65 (Flat sheet) & 0.528 & 44 & 171 & 384 & 688 & 1210 \\
\hline & 0.47 (Profile-sheet) & 0.528 & 4.9 & 9.5 & 21 & 42 & 228 \\
\hline
\end{tabular}

Experimentally load vs strains were measured by electronic strain gauge. Then load was converted to equivalent stresses using LUSAS. These parabolic and cylindrical roofing elements were a complex geometry due to presences of corrugation. It was quiet difficult to find out equivalent stress under UDL using classical formulla. The scalar stress state obtained by combining the individual component stresses at a point according to the classical von Mises failure criterion which is known as generalised stress, equivalent stress, von Mises stress or effective stress. The equivalent stress is most universally accepted yield criterion for metals (LUSAS Theory Manual, 2003) [28]. Stress - strain graphical presentation are shown in Figures 24, 25, 26, 27 and 28. 


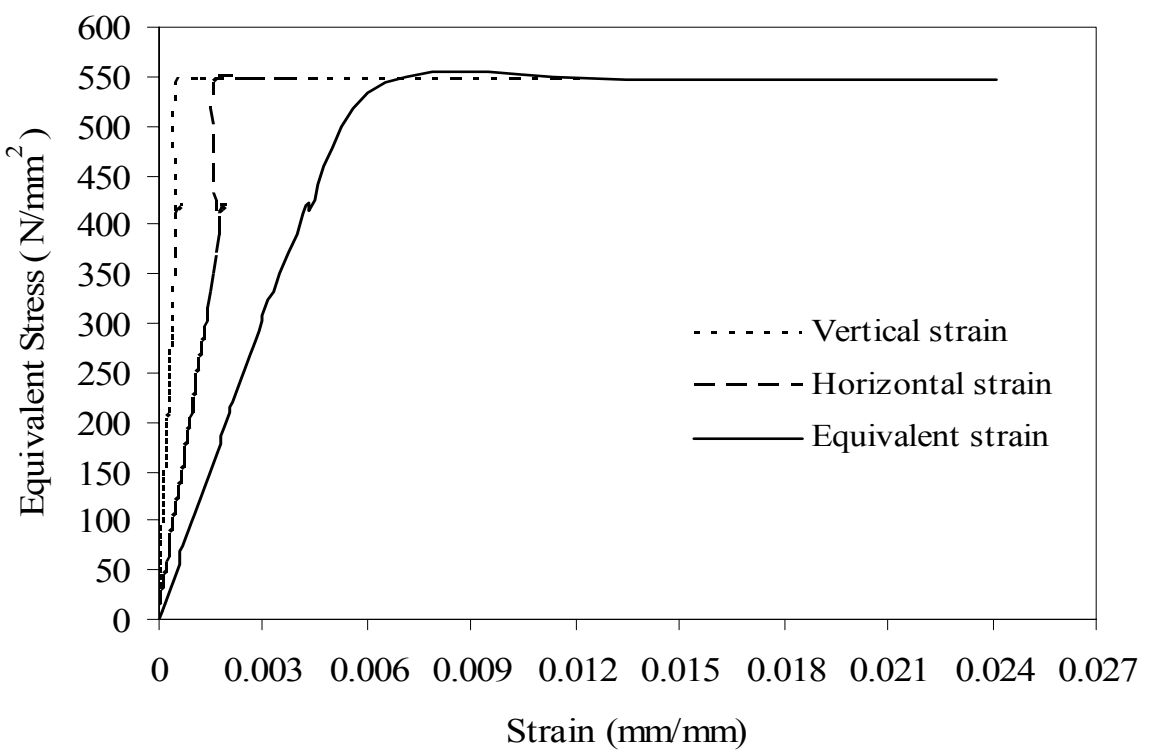

Figure 24. Stress-strain profile at crown of parabolic roofing element for $0.125 \mathrm{~m}$ crown height

The failure occurs when the energy of distortion reaches the same as energy for yield/failure in uniaxial tension. Mathematically, this is expressed as:

$$
F(\sigma, \kappa)=\sigma-\kappa\left(e^{-p}\right)=0
$$

Where $\quad \bar{\sigma}=\sqrt{3}\left(J_{2}\right)^{1 / 2}$

Equivalent, generalized or effective stress $\bar{\sigma}$ is calculated by the following formula.

$$
\frac{1}{2}\left[\left(\sigma_{1}-\sigma_{2}\right)^{2}+\left(\sigma_{2}-\sigma_{3}\right)^{2}+\left(\sigma_{3}-\sigma_{1}\right)^{2}\right] \leq \sigma_{y}^{2}
$$

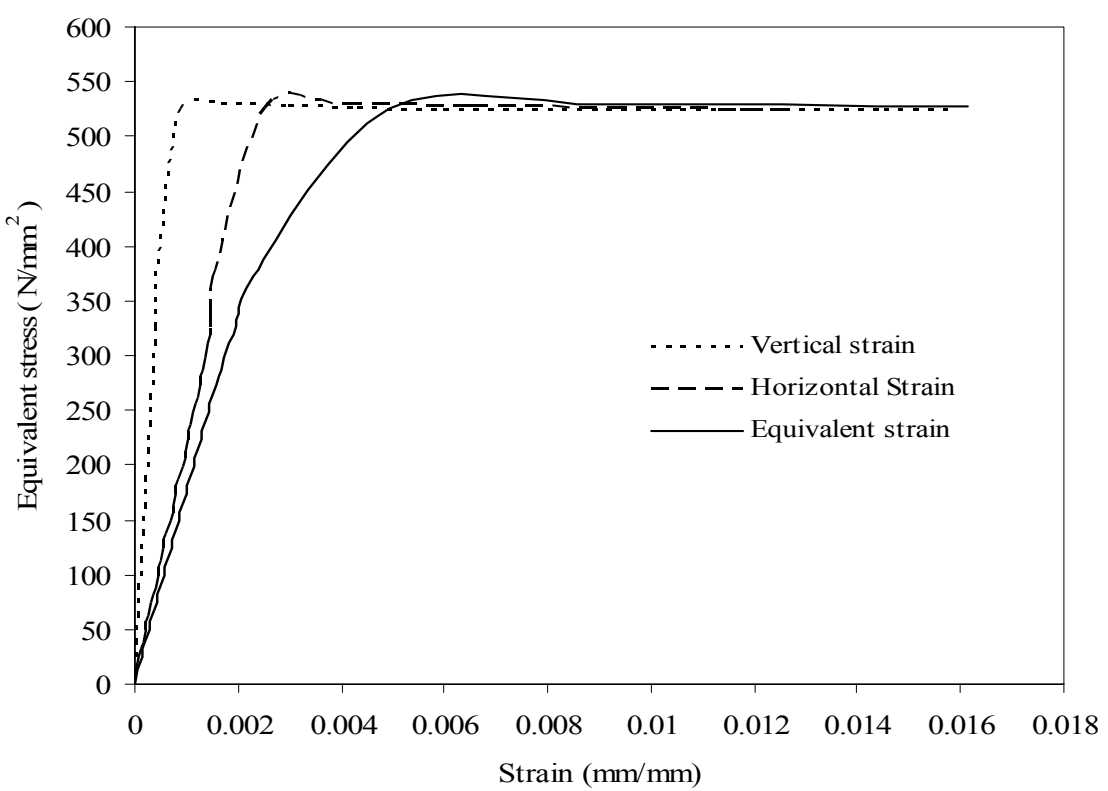

Figure 25. Stress-strain profile at crown of parabolic roofing element for $0.25 \mathrm{~m}$ crown height 


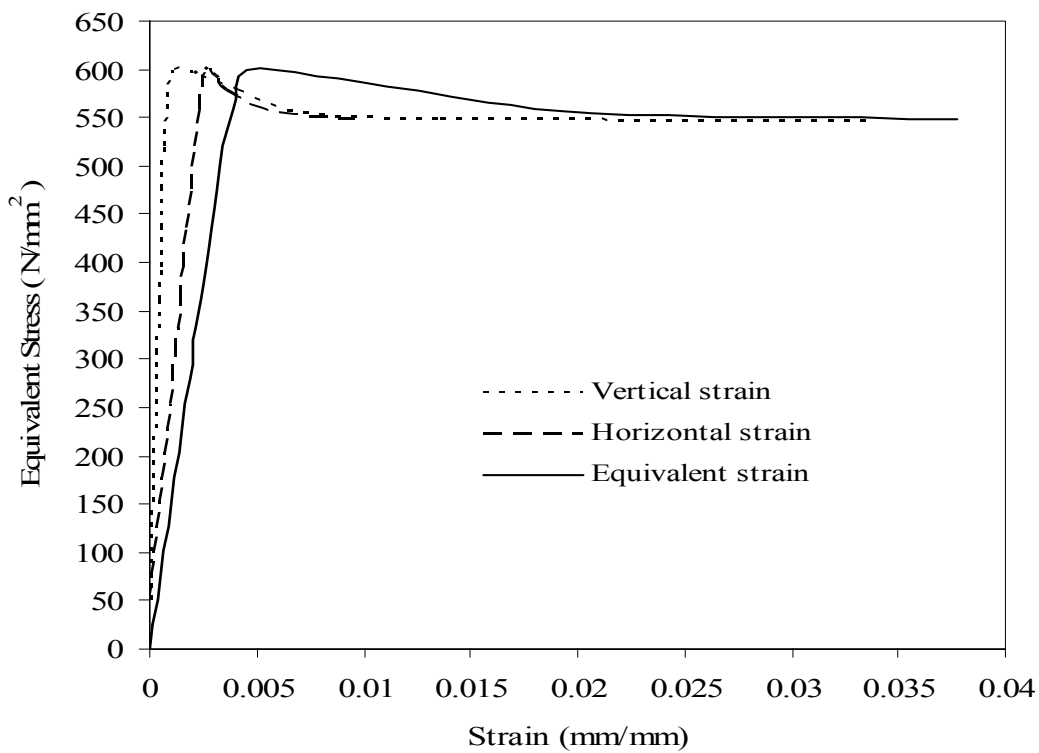

Figure 26. Stress-strain profile at crown of parabolic roofing element for $0.5 \mathrm{~m}$ crown height

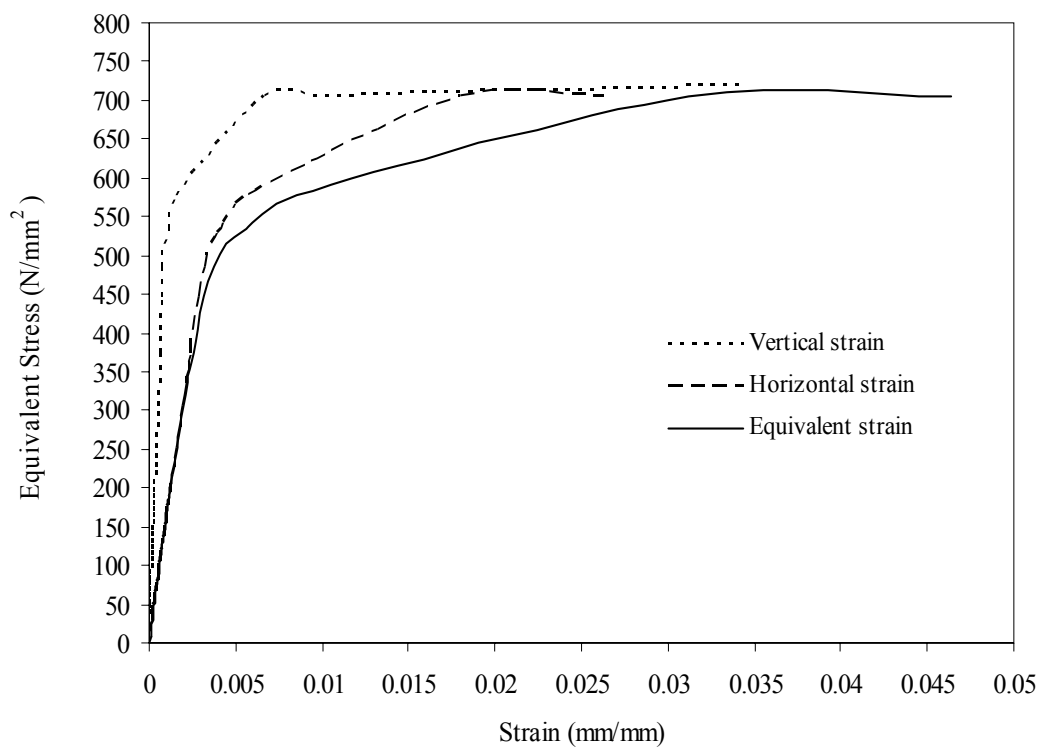

Figure 27. Stress-strain profile at crown of parabolic roofing element for $1.0 \mathrm{~m}$ crown height

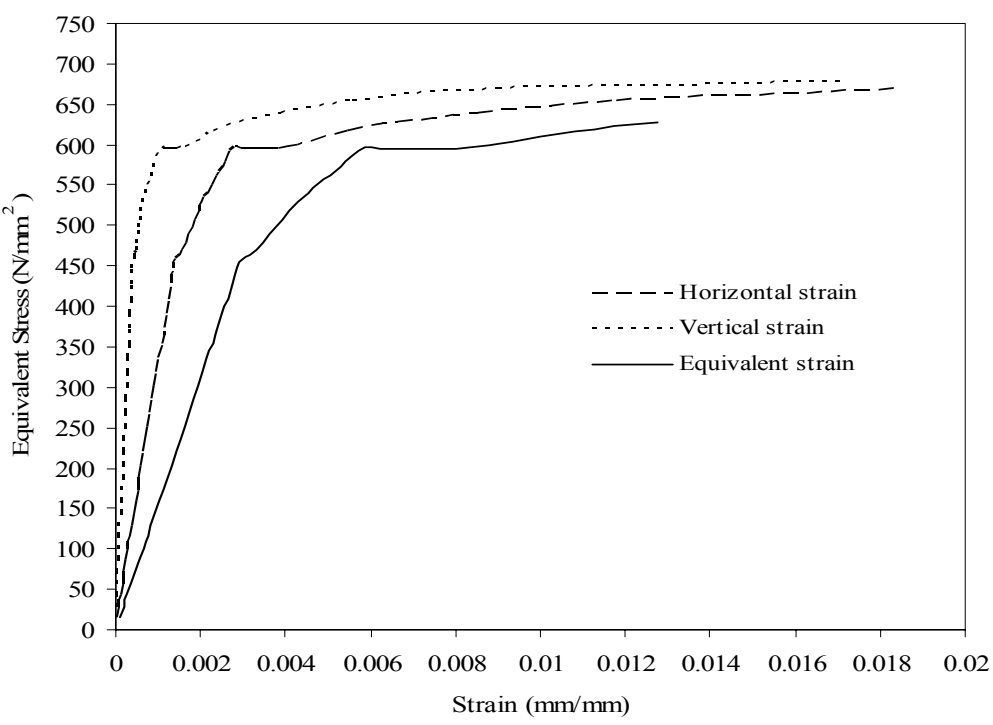

Figure 28. Stress-strain profile at crown of parabolic roofing element for $1.5 \mathrm{~m}$ crown height 


\section{DEFLECTED SHAPE}

In order to validate the proposed models a comparison between analytical and experimental deflected shape were carried out as shown in Figures 29 to 38. It was found that when the crown height of parabolic shape was increased, the central deflection decreased until optimum crown height.

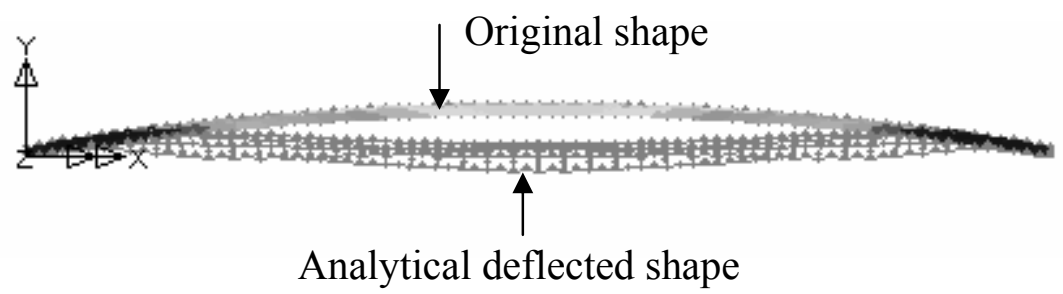

Figure 29. Analytical deflected shape of $0.125 \mathrm{~m}$ crown height parabolic roofing element

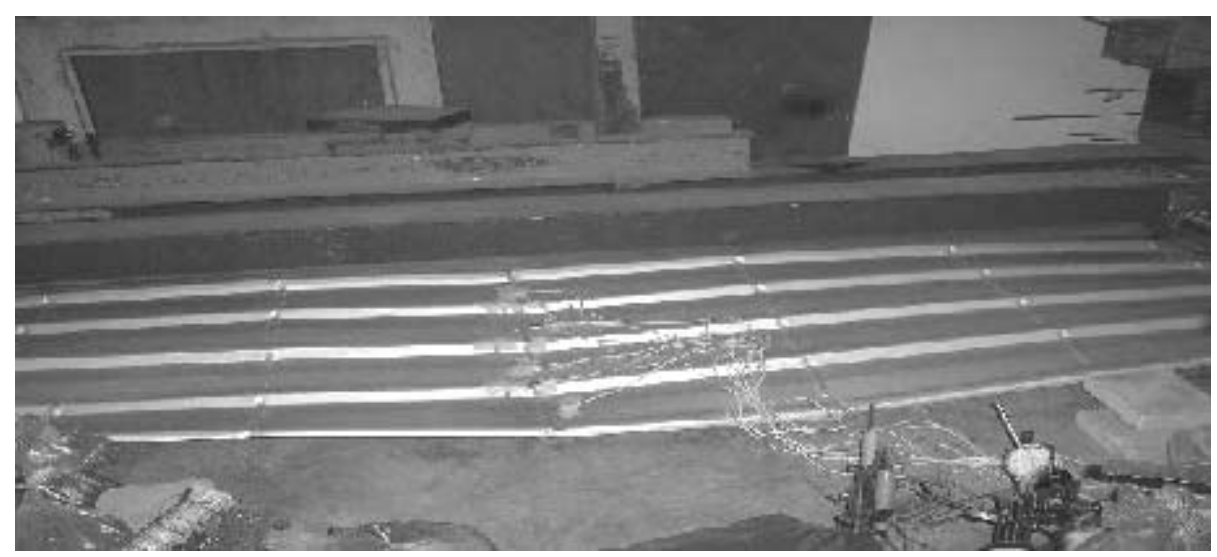

Figure 30. Experimental deflected shape of $0.125 \mathrm{~m}$ crown height parabolic roofing element

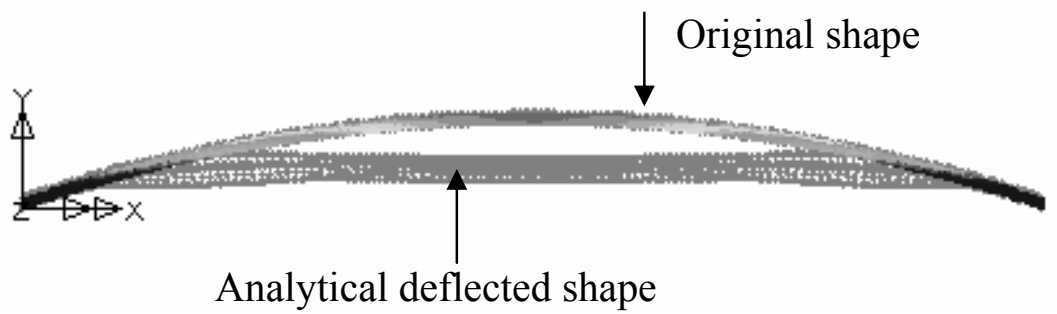

Figure 31. Analytical deflected shape of $0.25 \mathrm{~m}$ crown height parabolic roofing element

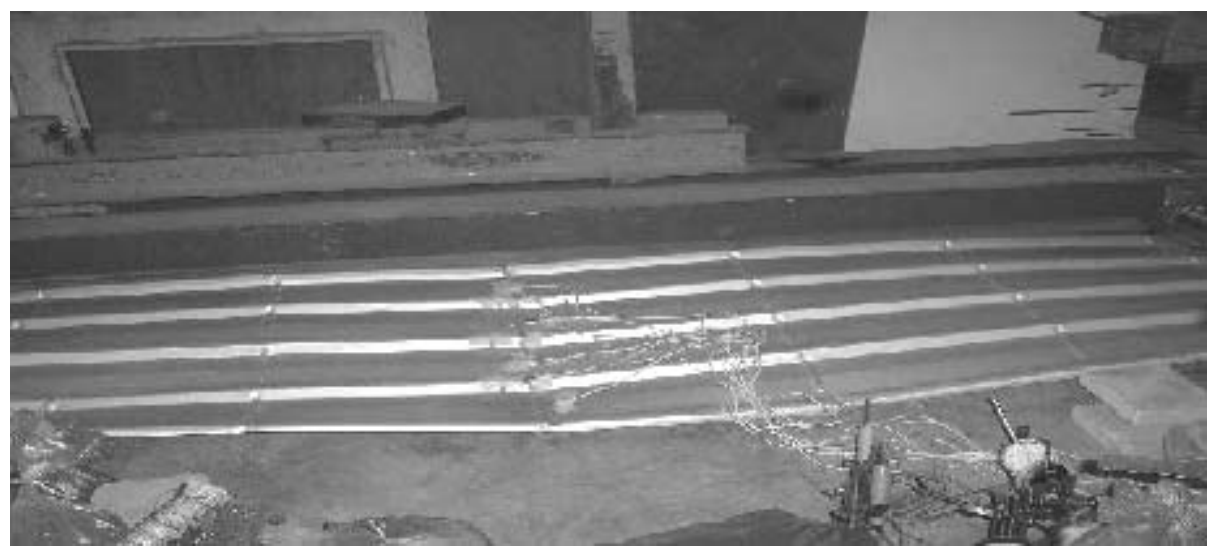

Figure 32. Experimental deflected shape of $0.25 \mathrm{~m}$ crown height parabolic roofing element 


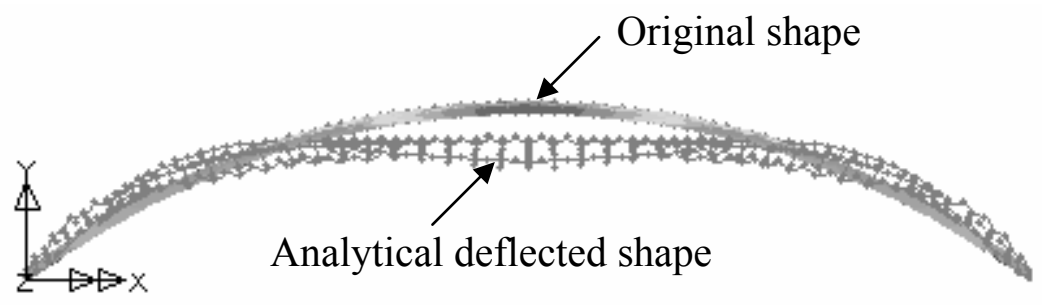

Figure 33. Analytical deflected shape of $0.5 \mathrm{~m}$ crown height parabolic roofing element

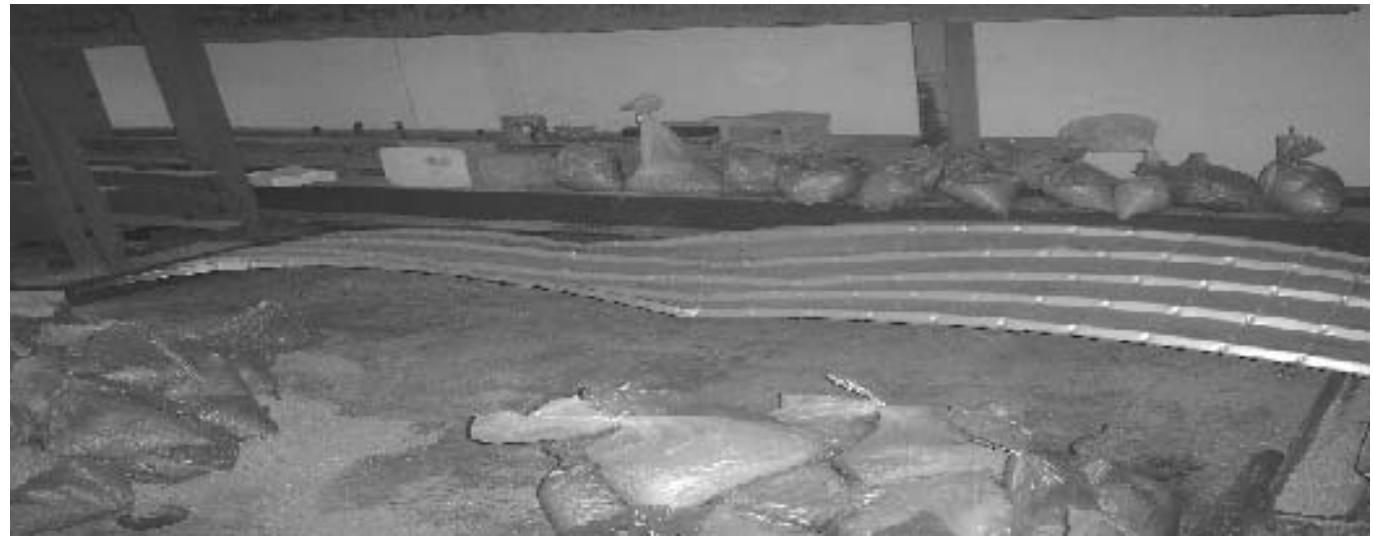

Figure 34. Experimental deflected shape of $0.5 \mathrm{~m}$ crown height parabolic roofing element

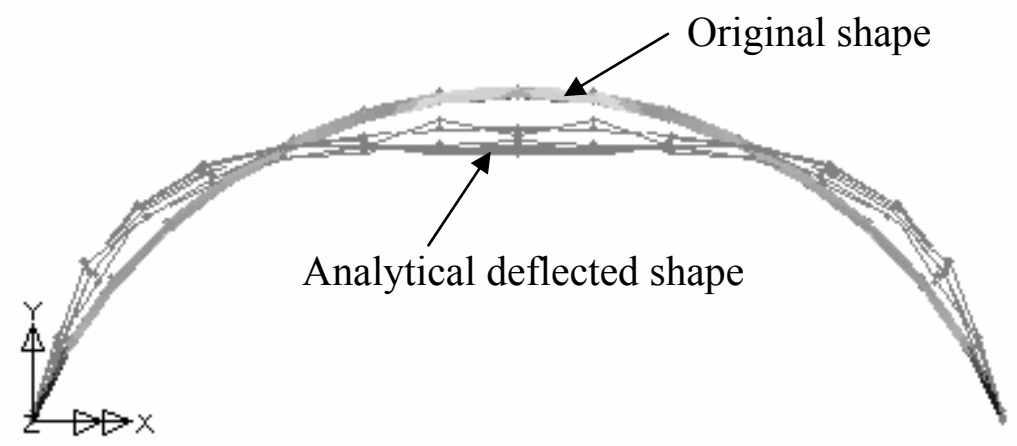

Figure 35. Analytical deflected shape of $1.0 \mathrm{~m}$ crown height parabolic roofing element

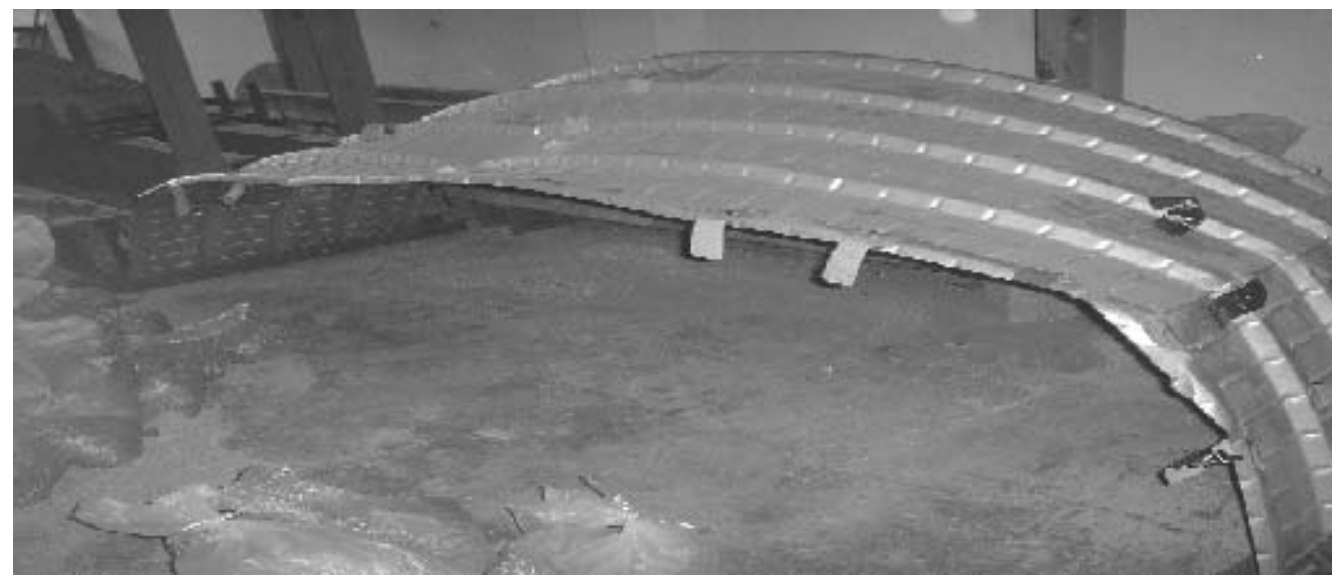

Figure 36. Experimental deflected shape of $1.0 \mathrm{~m}$ crown height parabolic roofing element 


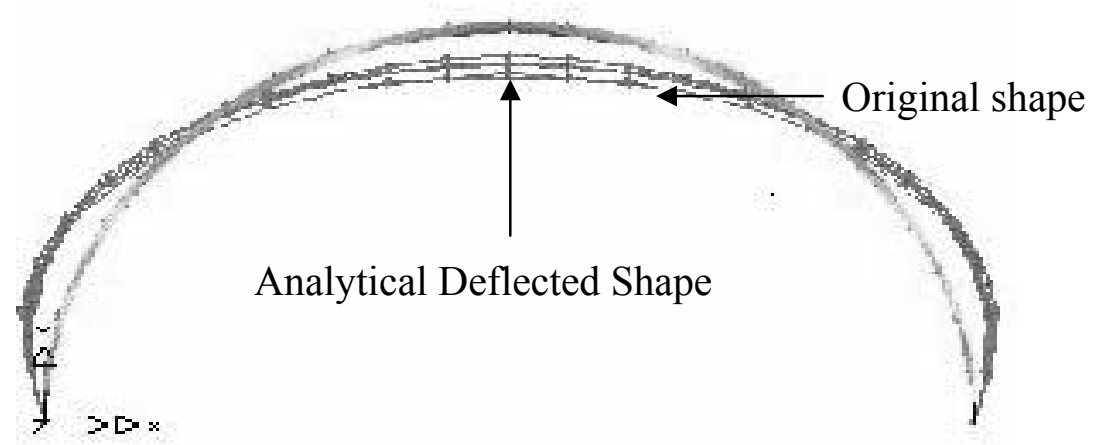

Figure 37. Analytical deflected shape of $1.5 \mathrm{~m}$ crown height cylindrical roofing element

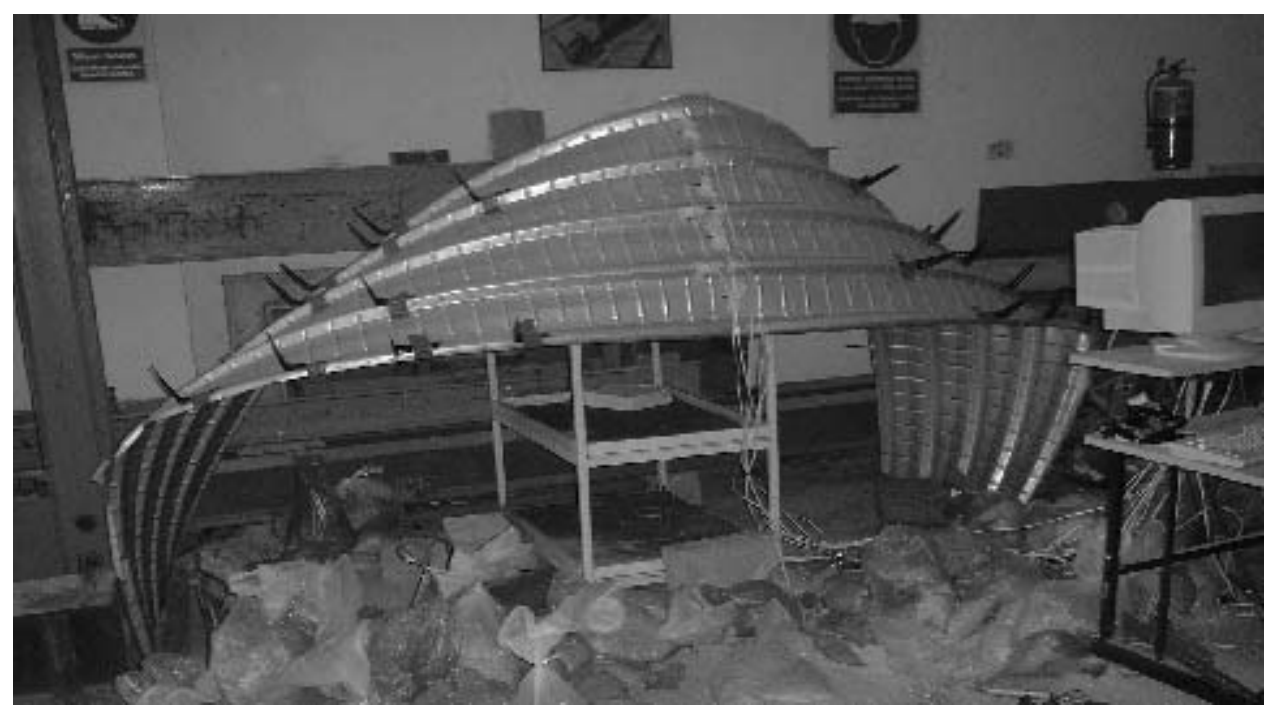

Figure 38. Experimental deflected shape of $1.5 \mathrm{~m}$ crown height cylindrical roofing element

\section{DETAILED STUDY ON 8M PARABOLIC ROOFING ELEMENTS}

The FEM investigation was extended to explore the feasibility of usage of zincalume as a selfsupporting roofing system. Based on FEM investigation and experimental validation, this study was extended up to $8 \mathrm{~m}$ span using $1.33 \mathrm{~m}$ crown parabolic roofing element for using as self-supporting condition for affordable quality housing. According to the FEM results analysis, it was seen that the parabolic roofing element can be used efficiently as a self supporting roofing system using $8 \mathrm{~m}$ span and $1.25 \mathrm{~mm}$ thick profile zincalume sheet for affordable quality housing. Load- deflection and stress-strain graphical presentation are shown in Figures 39 and 40 respectively.

The stress distributions along the arc of $8 \mathrm{~m}$ span parabolic roofing elements were observed with stress contour plot. It was seen that the stresses were not uniformly distributed all over the element. Maximum equivalent stress $406.1 \mathrm{~N} / \mathrm{mm}^{2}$ was found at the lower part of the element, which is connected with the support. The displacement distribution of $8 \mathrm{~m}$ parabolic roofing elements was observed by Displacement contour plot. The maximum displacements obtained at crown height were $39.69 \mathrm{~mm}$, under service load $0.612 \mathrm{kN} / \mathrm{m}^{2}$. Deflection and equivalent stress obtained within permissible limit $40 \mathrm{~mm}$ and $550 \mathrm{~N} / \mathrm{mm}^{2}$ respectively. 


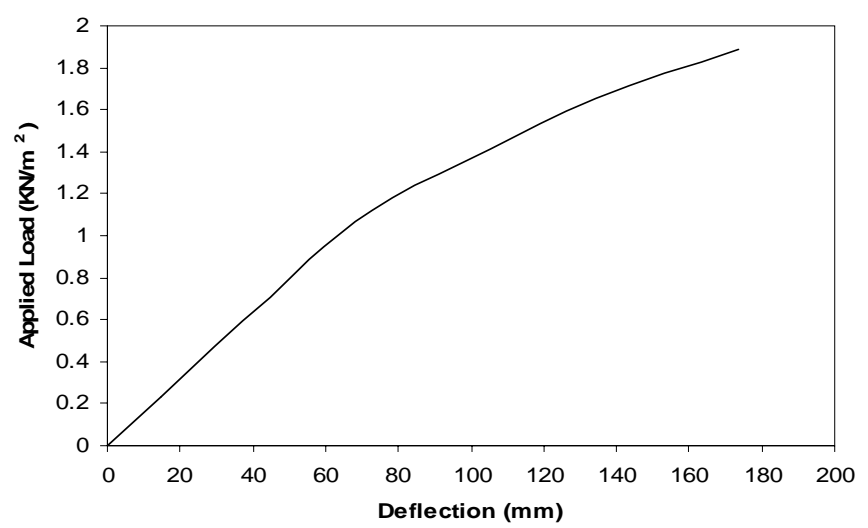

Figure 39. Load -deflection profile of $8 \mathrm{~m}$ span parabolic roofing elements

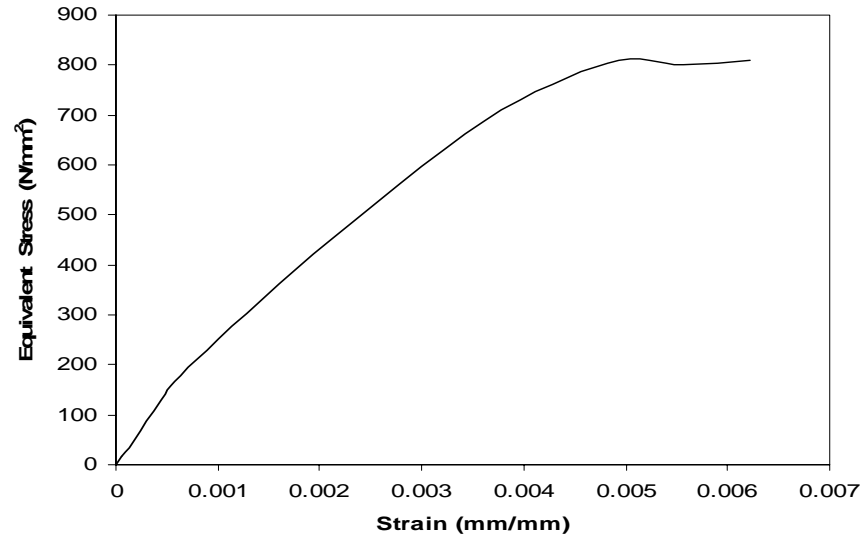

Figure 40. Stress-strain profile at crown of $8 \mathrm{~m}$ span parabolic roofing elements

\section{COST ANALYSIS}

The cost of the various zincalume roofing elements $\left(\right.$ per $\mathrm{m}^{2}$ ) are computed based on the material market cost in Kula Lumpur, Selangor Darul Ehsan, Malaysia. Zinaclume is manufactured mechanically in Bluescope Lysaghat Sdn Bhd. So, labour costs are included in its market prize. As a self-supporting condition, that easily can be handled and erected. So, labour cost will be very lower. Hence, labour cost of erection was not considered in this cost analysis. The cost analysis of zincalume roofing element as self-supporting condition is shown in Table 3

Table 3. Cost analysis for different types of roofing elements with $3 \mathrm{~m}$ span

\begin{tabular}{|l|l|c|c|c|}
\hline Material-s & Roofing elements types & $\begin{array}{c}\text { Quantity } \\
\left(\mathrm{m}^{2}\right)\end{array}$ & $\begin{array}{c}\text { Rate } \\
\left(\mathrm{RM} / \mathrm{m}^{2}\right)\end{array}$ & Cost (RM) \\
\hline Lysaghat Crim & Cylindrical( C.H.-1.5 m) & 3.58 & 33.5 & 120.0 \\
Curve Trimdek Hi- & Parabolic (C.H.-1.0 m) & 2.90 & & 97.25 \\
Tensile Zinaclume & Parabolic (C.H. 0.5 m) & 2.44 & & 81.84 \\
$(0.47 \mathrm{~mm}$ thickness) & Parabolic (C.H. 0.25 m) & 2.33 & & 77.92 \\
& Parabolic (C.H.125 m) & 2.29 & & $76.74^{*}$ \\
& Inverted V (C.H.0.5 m) & 2.40 & & $80.40^{*}$ \\
& Doubly curve (C.H. 0.5 m) & 2.46 & & $82.41^{*}$ \\
& Single pitch (C.H.0.5 m) & 2.31 & & $77.43^{*}$ \\
& Flat plane shape & 2.28 & & $76.38^{*}$ \\
\hline
\end{tabular}

Note: * Structurally not efficient

C.H. - Crown Height

\section{CONCLUSIONS}

Conventionally, metal sheet such as zincalume is using in roof covering through truss as a costume. It has been implemented a novel and new approach to provide self- supporting roofing system. The behaviour of nine different types of roofing element is studied to find out an economical, efficient, architecturally pleasing shape in self -supporting condition. Nonlinear effect has been adopted in the finite element analysis. From the parametric study, it is found that the central deflection and stresses are lower in parabolic shape of roofing element with crown height about 1/6 of chord length. Optimum crown height is obtained at about crown height $1 / 6$ of chord width due to higher load carrying capacity and lower deflection and stress. Internal horizontal reaction in parabolic shape roofing element always reduced shear force and bending moment. 
On the basis of the present analysis, it is found that the corrugated zincalume shell element is the most economical, efficient, architecturally pleasing shape in self- supporting condition. Based on the results obtained, the objectives of this work have been achieved where the parabolic corrugated roofing element showed significant improvements to the roof's structural performance. It was observed that corrugated parabolic shell element which, have $8 \mathrm{~m}$ span and $1.25 \mathrm{~mm}$ thickness could be used efficiently as self -supporting roofing system in housing construction.

\section{ACKNOWLEDGEMENTS}

The authors would like to thank the Construction Industry Development Board (CIDB) Malaysia for financial support and Blue scope Lysaght (Malaysia) Sdn Bhd for the free supply of experimental test specimens. The present study is part of graduate research of civil engineering department, Universiti Putra Malaysia (UPM) and National Research Programme on Affordable Quality Housing.

\section{REFERENCES}

[1] Jagannath, V. and Sekar, U.C., "Precast L-pan roof elements for low cost housing", Journal of Engineering Mechanics, 1992, 120(1), pp.120-113.

[2] Capurso, M., "Critical loads of self-supporting cylindrical shell roofs", International Journal of Solids Structure, 1967, 3, pp.117-141.

[3] Nilson, A.H., "Folded plate structures of light gauge steel”, ASCE transactions paper, 1963, 128(II), pp.848-880.

[4] EL-Atrouzy, M.N., "Cylindrical shell roofs made of corrugated metal sheets", Proceedings of the Fourth International Symposium on Roofing Technology, pp.138-141.

[5] Sakla, S.S., and Elbeltagi, E., "Design of Steel roofs subjected to drifted snow using genetic optimization", Computer and Structure, 2003, 81, pp.339-348.

[6] Rao, P.S. and Rao, A.P., "Behavior of cylindrical shells subjected to support settlement", Journal of Structural Engineering, 1988, 114(4), pp.931-941.

[7] Kostem, C.N., and Garrabrant, M.E., "The Effect of vertical support settlements on cylindrical shells", IASS Conference on Light-Weight Shell and Space Structures for Normal and Seismic Zones, Alma-Ata, 1977, USSR, pp.187-191.

[8] Simmonds, S.H., "Effect of support movement on hyperbolic paraboloid shells", Journal of Structural Engineering, 1989, 115(1), pp.19-31.

[9] Stekelenburg, P.J.Van., Walraven, J.C. and Mathews, M.S., "Development of semi cylindrical ferrocement roofing system", Journal of Ferrocement, 1980, 10(2), pp.111-118.

[10] Imam, N., Maity, D. and Kalita, U.C., "An investigation on the shape of ferrocement roofing elements", Journal of Ferrocement, 2002, 32(4), pp.271-286.

[11] Maity, D., Imam, N. and Kalita, U.C., "Finite element analysis of ferrocement roofing shell elements", International Conference on Construction Management and Materials (CONMAT), 2003, pp.285-294.

[12] Scordelis, A.C. and Lo, K.S., "Computer Analysis of Cylindrical Shells", ACI Journal, 1964, 61, pp.539-561.

[13] Zahurul-Islam, S.M., Abang-Ali, A.A and Jaafar, M.S., "An Investigation on the Shape of Thin Shell Metal Elements to Develop Self-supporting Roofing System”, International Conference on World Innovation of Structural Engineering WISE, Hyderabad, Andhra Pradesh, India, December 1-3, 2004, pp.42-50.

[14] Abang-Ali, A. A., Zahurul, S. M. and Jaafar, M.S., "Self -supporting Roofing System for Affordable Quality Housing, National Conference on Affordable Quality Housing”, Miri, Sarwak, Malaysia, November, 2004, pp.15-21. 
[15] Farshad, M., "Design and Analysis of Shell Structures", Kluwer Academic Publishers, The Netherlands, 1992, pp.2-39.

[16] LUSAS version 13.5-7, "Finite Element System", Powerful FE technology for specialist applications, UK, FEA Ltd, 2003.

[17] Martins, R.A.F and Oliveira, C.A.M., "Semi-loof Shell, Plate and Beam Elements-New Computer Versions: Part 1. Elements Formulation", Engineering Computer, 1988, 1(5), pp.15-25.

[18] Sze, K.Y., "Simple Semi-Loof Element for Analyzing Folded -Plate Structures”, Structural Engineering, 1989, 115(1), pp.19-31.

[19] Rao, P.S. and Rao, A.P., "Support settlement in continuous cylindrical shell roofs", Journal of Structural Engineering, 1986, 112(8), pp.1781-1795.

[20] Zienkiewcz, O.C., "The Finite Element Method", Third edition, McGraw-Hill, UK, 1979, pp.398-422.

[21] Huang, H., "Static and Dynamic Analysis of Plates and Shell", Springer-verlag, Berling Heidelberg, 1989, pp.67-83.

[22] Krishnamoorthy, C.S., "Finite Element Analysis theory and programming" (Second edition). New Delhi: Tata McGraw-Hill Publishing Company Limited, 2001, pp.465-510.

[23] Uniform Building by Law, Malaysian Standard Code of Practice, 1998, pp.34-37.

[24] BS 5427: Part 1: Code of Practice, "The use of profiled sheet for roof and wall cladding on building", British Standards Institution, 1996, pp.14-15.

[25] BS 6399: Part 1: Design Loading for Building, "Code of Practice for Dead and Imposed Loads", British Standards Institution, 1996, pp.2-3.

[26] CP 3: Chapter V: Part 2: Wind Loads. "Code of Basic Data for the Design of Building", British Standards Institution, 1972, pp.4-29.

[27] Zahurul-Islam, S.M., "Structural Strength and Behaviour of Cylindrical Steel Sheet Roofing", Master Thesis, Civil Engineering Department, Universiti Putra Malaysia, March 2006, pp.33-98.

[28] LUSAS Finite Element System, “LUSAS theory manual”, FEA Ltd, UK., 2004. 